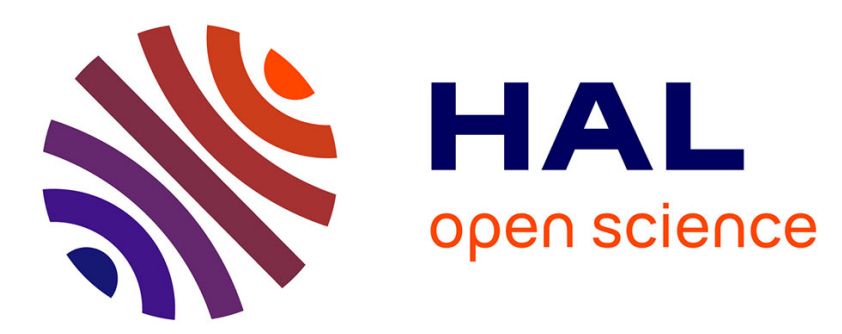

\title{
Autour des terres du Loñ Śrīviṣṇu et de sa famille : un document administratif du Cambodge angkorien, l'inscription K. 1238
}

\author{
Arlo Griffiths, Dominique Soutif
}

\section{- To cite this version:}

Arlo Griffiths, Dominique Soutif. Autour des terres du Loñ Śrīviṣnu et de sa famille : un document administratif du Cambodge angkorien, l'inscription K. 1238. Bulletin de l'Ecole française d'ExtrêmeOrient, 2008, 95-96, pp.29-72. 10.3406/befeo.2008.6104 . halshs-02103863

\section{HAL Id: halshs-02103863 \\ https://shs.hal.science/halshs-02103863}

Submitted on 18 Apr 2019

HAL is a multi-disciplinary open access archive for the deposit and dissemination of scientific research documents, whether they are published or not. The documents may come from teaching and research institutions in France or abroad, or from public or private research centers.
L'archive ouverte pluridisciplinaire HAL, est destinée au dépôt et à la diffusion de documents scientifiques de niveau recherche, publiés ou non, émanant des établissements d'enseignement et de recherche français ou étrangers, des laboratoires publics ou privés. 


\title{
Autour des terres du Loñ Śrīvișṇu et de sa famille : un document administratif du Cambodge angkorien, l'inscription K. 1238
}

\author{
Arlo GrifFIths \& Dominique SoutIF*
}

Les découvertes de nouvelles inscriptions de l'ancien pays khmer se multipliant depuis la réouverture du Cambodge, l'une des tâches prioritaires des épigraphistes est aujourd'hui de donner accès à un nombre croissant de textes inédits. Par son caractère relativement original, l'inscription que nous publions ici (ill. 1) enrichit agréablement le corpus épigraphique. S'écartant des préoccupations religieuses ou politiques habituelles, elle vient en effet s'ajouter au petit nombre d'inscriptions « juridiques », souvent attribuables comme elle au règne de Sūryavarman $\mathrm{I}^{\mathrm{er}}$ (première moitié du XI $\mathrm{I}^{\mathrm{e}}$ siècle de notre ère), et apporte de nombreux enseignements sur des aspects administratifs de la civilisation khmère.

\section{Provenance}

L'inscription a été signalée au programme « Corpus des inscriptions khmères 》 le 19 juillet 2006 par le propriétaire d'une collection privée située à Bangkok, dans laquelle elle était entrée depuis peu. À cette occasion, il nous a communiqué une couverture photographique complète de l'inscription, sur laquelle est fondée l'édition présentée cidessous ${ }^{1}$. Un examen de la pierre a également pu être effectué par D. Soutif le 25 juillet 2006, afin de la documenter et d'effectuer une lecture préliminaire du texte.

L'inscription avait déjà été inventoriée sous le numéro K. 1238 quand, en septembre 2007, la stèle est réapparue sur le marché de l'art et a été présentée dans une exposition organisée par une galerie d'art new-yorkaise (Kalista \& Rochell 2007) ${ }^{2}$. Elle était encore en vente dans cette galerie en avril 2008.

Malheureusement, le caractère probablement illégal de la découverte de cette stèle interdit d'en connaître la provenance exacte. Son ancien propriétaire à Bangkok n'a

* A. Griffiths est directeur d'études à l'EFEO, D. Soutif y est maître de conférences. - Ce travail
s'inscrit dans le cadre du programme " Corpus des inscriptions khmères " (EFEO/EPHE). Les deux
auteurs tiennent à remercier ici les relecteurs du BEFEO, anonymes ou non (Michael Vickery), qui
ont beaucoup contribué à améliorer cette étude. Une version précédente de l'édition et de la traduction
présentées ici avait été commentée par Philip N. Jenner en 2007 ; qu'il trouve ici l'expression de notre
gratitude pour les nombreuses corrections qu'il nous a suggérées. Il faut également signaler que cet
article a été rédigé avant la parution de son dictionnaire, ce qui explique qu'il n'y soit pas fait référence
(Philip N. Jenner, 2009, A Dictionary of Angkorian Khmer, Canberra, Pacific Linguistics). Des contri-
butions ponctuelles ont été faites par Annette Schmiedchen et Peter Bisschop et nous leur en sommes
également reconnaissants. 1. Ces clichés numériques ont été déposés à la photothèque de l'École française d'Extrême-Orient sous les numéros K. 1238-001 à 013.

2. Un cliché et une courte description de l'inscription sont présentés dans ce catalogue sous le numéro 66. 
d'ailleurs pas été en mesure de donner cette information. L'étude des toponymes et anthroponymes qui apparaissent dans l'inscription apporte peut-être un indice à ce sujet. Des soixante noms qui y sont relevés, vingt-cinq apparaissent en effet dans des inscriptions dont la provenance est connue. Certains d'entre eux étant mentionnés à plusieurs reprises, nous disposons en tout de quarante-quatre occurrences citées dans des inscriptions localisables (ill. 2).

La démarche consistant à cartographier la provenance de ces inscriptions a naturellement ses limites. Certains des toponymes sont par exemple très communs et donc susceptibles d'avoir été utilisés pour nommer plusieurs endroits différents, sans compter que rien n'assure que les sites qu'ils désignaient étaient proches de ceux d'où proviennent les inscriptions dans lesquelles ils sont cités. Le même problème se pose pour les noms de dignitaires, qu'ils soient associés ou non à des noms de lieux. On retrouve par exemple plusieurs d'entre eux dans les listes de fonctionnaires prêtant serment à Sūryavarman Ir qui sont gravées dans le pavillon d'entrée du palais royal d'Angkor Thom (K. 292; 933 śaka; IC III, p. 205). Dans ce cas, les personnes en question sont susceptibles de provenir de régions relativement éloignées d'Angkor et leurs noms ne sont donc pas pertinents pour déterminer la provenance de l'inscription.

Néanmoins, la répartition géographique des inscriptions où apparaissent ces quarantequatre occurrences inciterait plutôt à penser que K. 1238 provient du Cambodge, dans ses frontières actuelles, et même plus exactement du nord-ouest du pays, où sont concentrées les trois quarts d'entre elles. Cette concentration est encore plus frappante quand on sait que les occurrences relevées dans des inscriptions provenant du Sud du Cambodge sont majoritairement préangkoriennes. Dans le nord, à deux exceptions près, tous les cas ont été relevés dans des inscriptions angkoriennes contemporaines de $\mathrm{K} .1238\left(\mathrm{x}^{\mathrm{e}}-\mathrm{xl}^{\mathrm{e}}\right.$ siècle de notre ère). La densité d'occurrences relevées près d'Angkor n'a rien d'étonnant, étant donné l'importance relative de cette région et du corpus épigraphique qui y a été retrouvé. Sachant que K. 1238 est attribuable au règne de Sūryavarman I ${ }^{\text {er }}$ la même remarque peut s'appliquer à la région de Battambang où ce roi, en particulier, a réalisé plusieurs fondations importantes (Vat Baset, Vat Ek, etc.). On y connaît par conséquent nombre d'inscriptions datant de la première moitié $\mathrm{du} \mathrm{XI}^{\mathrm{e}}$ siècle de notre ère, dans lesquelles on trouve des mentions des fonctionnaires de ce souverain et donc de leur nom ou de celui des localités auxquelles ils étaient associés. En revanche, la concentration d'occurrences dans l'extrême nord-ouest est plus inattendue ; bien que la voie royale conduisant aux grands sanctuaires de l'actuelle Thaillande passe par cette région, le nombre d'inscriptions qui y ont été retrouvées reste plus limité. Si l'on devait absolument estimer une provenance à partir de cette carte, nous pencherions donc pour la province de Banteay Mean Chey ou même celle d'Oudor Mean Chey, d'autant que ces régions sont particulièrement confrontées aux problèmes de pillage.

Cependant, il est également intéressant de ne prendre en compte que les toponymes étroitement associés aux faits rapportés dans l'inscription, et donc plus susceptibles de nous fournir des indications précises sur sa provenance. Ils sont de deux types, mais peu d'occurrences ont pu être identifiées. En premier lieu, deux des lieux de provenance des protagonistes directement impliqués dans les transactions de terres qui sont l'objet de ce texte sont connus : le Travān Krave et le Sruk Jen̉ Chdin. Cependant, dans les deux cas, ces noms apparaissent à la fois dans des inscriptions provenant des régions d'Angkor et 
de Battambang et n'aident donc pas à identifier la provenance de K. $1238^{3}$. Pour ce qui concerne les noms de terres et de communes qui sont l'objet de ces transactions, une seule, une terre dite « de Travān La'ak », est attestée par ailleurs. Le nom de ce travāan, ou « bassin », apparaît également dans l'inscription K. 1229 (face C, 1. 40 ; 901 śaka ; Soutif 2009, p. 568), orthographié travān l'ak. Par chance, nous avons de bonnes raisons de penser qu'il s'agit bien du même site dans les deux textes. En effet, dans K. 1229, les bornes d'une terre sont déterminées par les terres de Travāñ L'ak et par la rive du Travān Krave, et K. 1238 nous apprend justement qu'une terre de Travān La'ak est détenue par des personnes provenant de Travān Krave (face A, 1. 7-11). En ajoutant à cela le fait que K. 1229 provient du Prasat Trapeang Khna, temple situé à quinze kilomètres au sudouest d'Angkor Thom (Christophe Pottier, comm. pers.) ${ }^{4}$, et que l'abornement dont il est question dans K. 1229 est limitrophe de terres appartenant au Phnom Bakheng (Vnam Kantāl $)^{5}$, on est plutôt tenté de penser que Travān L(a)'ak et Travān Krave désignent des sites de la région d'Angkor. Pour ce qui concerne K. 1229, pour autant que l'on sache, les terres en question pouvaient être relativement éloignées du Prasat Trapeang Khna où leur achat était commémoré. Pourtant, il s'agissait d'un sanctuaire assez modeste, que l'on serait tenté de penser assez proche de son patrimoine foncier. De même, il semble que K. 1238 ait été érigé à proximité des terres de Travān $\mathrm{L}(\mathrm{a})$ 'ak, lieu de fondation d'une commune et d'un linga de Śiva où des fonctionnaires royaux sont chargés de se rendre pour ériger l'inscription (face A, 1. 4-5). Bien que nous n'ayons pas d'indices formels, une provenance de la province de Siem Reap n'est somme toute pas incompatible avec les données du texte et ne doit donc pas être écartée 6 .

Ainsi, il reste difficile de proposer une provenance précise à partir des toponymes mentionnés dans ce texte, et il semble raisonnable de s'en tenir à une approximation au quart nord-ouest du Cambodge actuel. Que cette inscription provienne de la province de Siem Reap ou des provinces frontalières de la Thaïlande, on ne peut que regretter les circonstances illégales de sa découverte, en raison desquelles de nombreux points ne pourront peut-être jamais être éclaircis.

3. Travān Krave : K. 222, 1.6 (x śaka; Banteay Prāv : IK 782 ; IC III, p. 61, 63) et K. 1229, face C, 1. 44 (901 śaka; Prasat Trapeang Khna : IK 510 ; Soutif 2009, p. 568). Jeñ Chdin : K. 207, 1.58 (964 saka ; Vat Baset : IK 862 ; IC III, p. 19) et K. 467, 1.17 (933 śaka; Prasat Khleang Sud : IK 476.01 ; IC III, p. 218).

4. Le site est désigné sous le nom de Trao Treang (IK 510) par Lunet de Lajonquière (1911, p. 127); voir ill. 3.

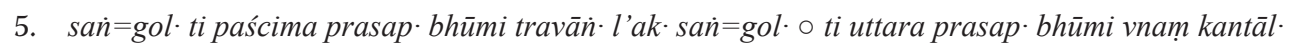
[...] san $=\mathrm{gol} \cdot \circ$ ti vāyavya gi gol $\cdot$ ta gi thnval $\cdot$ travāa $\cdot$ krave ti vāyavya $\odot$, « ils installèrent les bornes à l'ouest le long des terres de Travān L'ak; ils installèrent les bornes au nord le long des terres du Vnam Kantāl [...], ils installèrent les bornes au nord-ouest. Les bornes atteignent la rive du Travān Krave au nord-ouest 》 (K. 1229, face C, 1. 40-44 ; 901 śaka; Soutif 2009, p. 568, 575).

6. On notera que tous les personnages cités ne résidaient pas nécessairement à proximité du lieu où l'inscription était installée. Ainsi, quand une assemblée royale était convoquée pour juger d'une transaction ou d'un litige, il est possible que ses membres viennent de communes éloignées. En revanche, il est vraisemblable que des notables appelés à être témoins d'une transaction doivent connaître les lieux et donc être choisis dans le voisinage. Or, dans la liste de témoins des lignes 27-37 de la face A, l'un d'entre eux n'est autre que le Pādamūla du Prasat Ta Keo (face A, 1. 29, cf. commentaire, p. 40-41), ce qui soutiendrait bien l'hypothèse de la région d'Angkor. On notera également que ce dignitaire provenait de la commune de Vāruṇi, comme certains des propriétaires de la terre de Travān La'ak (face A, 1. 7-9). 


\section{Description physique}

La stèle portant K. 1238 est en grès gris à grain fin. Elle est haute de $117,5 \mathrm{~cm}-$ tenon de $23 \mathrm{~cm}$ compris -, large de $56,8 \mathrm{~cm}$ et d'une épaisseur de $5,5 \mathrm{~cm}$.

La taille de la pierre a été particulièrement soignée. Les contours et les dimensions sont en effet réguliers, la partie supérieure est en accolade double et, ce qui est plus exceptionnel, l'extrémité du tenon a également été traitée en accolade. Enfin, les deux grandes faces offrent des surfaces parfaitement planes et finement polies; elles sont respectivement inscrites de quarante-huit et trente lignes en khmer angkorien.

La stèle est brisée en cinq parties, mais elle a été reconstituée et ne présente qu'une seule lacune importante, à la fin de la ligne 11 de la face A. À cela, il faut ajouter quelques éclats et éraflures entraînant la perte, sur les deux faces inscrites, de quelques caractères, le plus souvent restituables avec certitude. On notera toutefois que certaines éraflures sont peut-être antérieures à la gravure de la stèle. En effet, il semble que l'une d'entre elles a poussé le lapicide à laisser un espace vierge au début de la ligne 19 de la face A.

À la qualité de préparation du bloc répondent une écriture soigneusement calligraphiée ainsi qu'une « mise en pierre » bien justifiée et occupant l'essentiel de la largeur de la stèle sur les deux faces inscrites (ill. 4 à 8). La régularité de l'écriture permet d'affirmer que l'ensemble du texte a été gravé au même moment, correspondant probablement, à peu de chose près, à la plus récente date mentionnée dans le texte, 958 de l'ère śaka, soit 1036 de notre ère.

Le texte relate des événements qui se sont déroulés sous le règne de Sūryavarman I Irr, en 958, 925, 946 et 948 de l'ère śaka. L'articulation du texte s'appuie sur une utilisation pertinente de la ponctuation qu'il est intéressant de présenter ici.

Comme c'est souvent le cas dans l'épigraphie khmère, et plus généralement en Asie du Sud-Est (Griffiths \& Southworth 2007, p. 352, n. 10), la ponctuation utilisée pour marquer le début du texte est au Cambodge sous le nom de gomūtra, « urine de vache », et était aussi utilisé dans les manuscrits jusqu'à l'époque moderne, pointe vers la droite, pour marquer la fin d'un paragraphe ou d'un texte (Antelme 2007, p. 47). Il s'agit selon toute probabilité d'une variante paléographique d'un signe liminaire assez répandu dans l'épigraphie et les manuscrits indiens. Bien que le gomūtra ait parfois été identifié à la syllabe om - notamment par Auguste Barth, dans une note préliminaire à l'édition par Abel Bergaigne de K. 323 (ISCC, p. 393, n. 1) -, il semble qu'il faut plutôt l'interpréter comme un symbole exprimant le mot siddham, « Succès! » (Roth 1986, p. 240 ; Sander 1986, p. 251).

La ponctuation finale de ce texte est composée d'un fleuron complexe encadré de doubles danda $\|$ 浔 $\|$. L'usage de ce type de signe est également assez répandu au Cambodge, où ils peuvent parfois prendre une taille importante ainsi qu'une certaine complexité, comme c'est le cas dans l'inscription préangkorienne K. 1214 (Griffiths 2005, p. 12, 42).

Parallèlement à cela, des fleurons plus simples à quatre pétales inscrits dans un cercle (8) sont placés devant les dates déjà évoquées pour souligner les grandes parties du texte (face A, 1. 39, 48 ; face B, 1. 17). Dans le dernier cas, ce signe est précédé d'un double danda. 
Deux types de ponctuations apparaissent dans cette inscription : ० (baña mān', « œuf de poule ») et $\odot$ (bhnaeka mān', « œil de poulet ») 7 . Si l'emploi de ces deux signes n'est pas toujours évident à distinguer, il semble pourtant que l'« œil de poulet » marque des ruptures plus importantes dans le texte. En effet, il n'apparaît que deux fois. Dans le premier cas (face A, 1. 15), il signale la fin d'une longue liste d'objets empruntés par plusieurs personnes et y met en valeur le total de ces biens. Dans le second cas (face B, 1. 4), il est utilisé pour souligner la répétition de la date et donc le début d'une sous-partie de la troisième partie (cf. le synopsis ci-dessous).

En revanche, l'« œuf de poule » est plus largement utilisé pour rythmer le texte et en faciliter la compréhension. On notera en particulier son usage pour structurer les listes de dignitaires. Ces derniers ne sont en effet pas systématiquement séparés par de tels signes ; il semblerait que la ponctuation ne soit précisée que pour lever une possible ambiguïté, notamment pour isoler des expressions complexes, comme à la ligne 23 de la face $\mathrm{A}$, où des « œufs de poule» encadrent l'expression kamsten் satyavikrama khloñ. gāp p patrakāra et permettent donc de comprendre qu'il s'agit bien d'une seule et même personne.

\section{Synopsis}

En dépit du soin accordé à la calligraphie, à la mise en forme et à la matérialisation de l'articulation de cette inscription, le sens du texte n'est pas évident à appréhender. Le caractère fortement administratif de ce texte entraîne en effet l'usage d'une forme d'expression particulière où le recours à des répétitions, des raccourcis, des citations d'archives administratives et des formulations techniques égare souvent le lecteur du $\mathrm{XXI}^{\mathrm{e}}$ siècle. Afin de faciliter l'accès à ce texte, il nous semble utile d'en proposer au préalable un synopsis.

\section{Ire partie (face A, l. 1-39)}

En 958 śaka (1036 de notre ère), le Vraḥ Kamraten 'Añ Śrī Narendravarman du sruk de Danlān, alors chef principal des cuisiniers, ayant donné à ses enfants - Loñ Śrīvișṇu et Ten Vija - une terre achetée au Varṇāśrama ${ }^{8}$, demande au roi Sūryavarman I ${ }^{\text {er }}$ de confirmer la donation en lui attribuant le statut de fondation royale. Il est précisé qu'un sruk, vraisemblablement Narendrālaya (face A, 1.38), a été fondé sur cette terre et qu'un Vrạ̣ Kamraten 'Añ Śivalinga y a été installé (face A, 1. 1-4).

Le roi ayant accédé à sa requête, des fonctionnaires de l'assemblée royale se rendent sur place pour transmettre l'édit au Varṇāśrama et ériger une inscription à cette occasion (face A, 1. 5-9). Les deux présidents de l'assemblée qui conduisent cette mission Prothivīndrapaṇịta et Rājendrapaṇụita - sont identifiés aux lignes A, 5-6 ; ils sont accompagnés de deux assesseurs et de deux greffiers dont les noms sont précisés plus loin (face A, 1. 19-20).

Tout d'abord, neuf des membres du Varnāśrama, présentés aux lignes A, 7-9 (nom, provenance, éventuellement titre et profession), sont interrogés et garantissent que les deux terres dont la propriété va être transmise relèvent « sans contestation » de leur autorité (face A, 1. 9-11). Six d'entre eux, auxquels vient s'ajouter un certain Loñ Vañ, reconnaissent ensuite s'être endettés auprès de Narendravarman afin d'être en mesure de

7. Comme dans le cas du gomütra, il s'agit ici des appellations traditionnelles de ces signes qui sont utilisés dans les manuscrits (Antelme 2007, p. 47).

8. Sur ce terme problématique, voir infra commentaire p. 54. 
s'acquitter de l'impôt royal ; ils acceptent alors de rembourser cette dette en lui donnant une des deux terres (face A, 1. 11-12). Les lignes A, 13-17 donnent la liste des biens empruntés, intérêts compris, qui composent cette dette et précisent les dimensions de la terre correspondant à leur valeur.

Suit (face A, 1. 17-24) une liste de vingt-cinq dignitaires ayant écouté cette déposition, liste qui débute par les six fonctionnaires de l'assemblée royale déjà évoqués aux lignes A, 5-7. Il semble que ce corps de fonctionnaires constitue l'assemblée royale au complet (cf. face A, 1. 25).

Les tenants et aboutissants de la transaction sont alors fixés. En présence de l'assemblée et des cédants (les membres du Varṇāśrama), les deux présidents transmettent ensuite l'édit qui accorde la validation royale à la donation en faveur de Śrīviṣnu et de Vija aux « notables, anciens de la commune et propriétaires terriens », qui sont témoins de l'abornement (face A, 1. 24-27), et dont la liste est donnée aux lignes A, 27-37.

À l'issue de l'évocation de ce premier transfert de propriété, est rapportée la consécration d'une seconde terre au Śivalinga du sruk de Narendrālaya, qui est placée sous l'autorité de Loñ Śrīvișnu et de Ten Vija. Parmi les donateurs figurent deux des membres du Varnāásrama mentionnés aux lignes A, 7-9. Les raisons qui les ont poussés à effectuer cette donation ne sont pas précisées ; rien ne laisse donc supposer que cette terre ait été acquise par Narendravarman avant d'être transmise à son fils (face A, 1. 37-39) ; l'utilisation du verbe jvan semble même exprimer précisément le fait que ce don est effectué directement en faveur de la divinité (cf. n. 89).

\section{II ${ }^{e}$ partie (face A, l. 39-48)}

La seconde partie relate des faits antérieurs de trente-trois ans environ à ceux de la précédente (1003 de notre ère), et qui apparaissent à première vue dénués de connexions avec le reste du texte, si ce n'est par la mention d'un Vrah Śivalinga, dont on peut présumer qu'il correspond au Vraḥ Kamrateñ 'Añ Śivalinga de Narendrālaya.

Elle rapporte le règlement d'un litige foncier opposant le plaignant Loñ Las - qualifié de « jeune chanteur »- aux Loñ Bhīma et $\mathrm{Ne}$, à propos de six rizières dont les fruits assuraient une redevance mensuelle au Vrạ Śivalinga. Les raisons du litige ne sont pas précisées. Comme c'est l'usage, la première étape de l'instruction mentionnée est l'envoi d'un enquêteur chargé d'établir l'« origine et l'histoire » de ces terres (A, 1. 39-41) ${ }^{9}$.

Aux lignes A, 41-43, un ordre royal charge deux dignitaires de se rendre sur place accompagnés des deux parties, afin d'enquêter auprès des anciens de la commune et des propriétaires terriens et de dresser un plan des terres en question.

Les résultats de cette instruction semblent peu compter dans le verdict. En effet, bien que le plan ait été remis à l'assemblée royale, les lignes A, 43-48 insistent davantage sur le rôle décisif du comportement des deux parties au cours des sept mois pendant lesquels le procès semble s'être éternisé. Le Loñ Las, jeune chanteur, en sort vainqueur.

\section{III ${ }^{e}$ partie (face A, l. 48 à face B, l. 30)}

La troisième partie se décompose elle-même en trois sous-parties. Les faits rapportés sont comparables à ceux de la première partie. Un débiteur, le Loñ Nārāyaṇa, s'acquitte d'une dette par un transfert de propriété foncière, la terre étant alors transmise à la famille

9. À ce sujet, voir de Mestier du Bourg 1968, p. 39. Dans K. 1238, on ne relève que le nom cāre et non le composé sabhācāre, « enquêteur de l'assemblée », cité par de Mestier du Bourg. On peut toutefois présumer que l'expression cāre 'āya vraḥ sabhā, " enquêteur de l'assemblée royale », en est un équivalent (face A, 1. 42). À ce sujet, cf. également Sahai 1970, p. 103. 
du créditeur, le Mratāñ Khloñ de Danlān. C'est au niveau de ces deux personnes que le lien avec le reste du texte va apparaître. En effet, des indices vont progressivement permettre de reconnaître dans ces deux protagonistes le Loñ Las, « jeune chanteur », de la deuxième partie, et le V. K. 'A. Śrī Narendravarman du sruk de Danlān de la première ${ }^{10}$.

Première sous-partie ( $A, l .48$ à $B, l .2)$. Un personnage, s'exprimant à la première personne, rapporte avoir conduit le Loñ Nārāyaṇa en 946 śaka (1024 de notre ère) devant l'assemblée royale, Nārāyaṇa lui ayant emprunté de l'or, du cuivre et divers objets précieux à une date qui n'est pas mentionnée. Aux lignes B, 2-4, le narrateur ajoute que Nārāyaṇa lui a remis quatre petites rizières et une résidence pour prix de cette dette, biens fonciers qu'il a lui-même transmis à son fils, le Loñ Śrīviṣnu, et à d'autres membres de sa famille. L'identité de son fils permet déjà d'identifier ce narrateur à Narendravarman. Contrairement à la partie précédente, la confrontation devant l'assemblée royale n'est pas liée au règlement d'un litige : elle n'a pour but que de faire entériner la transaction par l'assemblée après audition des différentes parties concernées par ce double transfert de propriété : Nārāyaṇa, le narrateur et sa famille.

Deuxième sous-partie (B, l. 4-17). Le détail de l'audience est alors précisé. Des membres de l'assemblée récapitulent d'abord au Loñ Nārāyaṇa tous les détails de la transaction, qui sont rassemblés dans un édit royal. Ils rappellent qu'en remboursement des biens déjà mentionnés, quatre rizières et une résidence ont été données en droit exclusif au M. Kh. de Danlān, que l'on peut donc identifier au narrateur de la première sous-partie ; on doit alors supposer que ce dignitaire a reçu le titre de V. K. 'A. Narendravarman ${ }^{11}$ entre 946 et 958 de l'ère śaka. L'assemblée royale insiste également sur le fait que Nārāyaṇa ne doit plus utiliser les rizières en question pour s'acquitter de ses redevances envers le roi ou les dieux (face B, 1. 4-8). Enfin, il est ajouté que conformément au témoignage du M. Kh. de Danlān, le droit exclusif sur ces terres a été transféré à des membres de sa famille. Le Loñ Nārāyaṇa ayant admis les faits sous serment, un acte officiel est préparé par un enquêteur et transmis à un président de l'assemblée royale, qui confirme le droit des descendants du Mratāñ Khloñ sur la foi de ce document (face B, 1. 8-12). La procédure, déjà répétitive, n'est pas complète pour autant. Avant d'être validé, ledit document est encore une fois soumis par Nārāyaṇa et le M. Kh. de Danlān à des membres de l'assemblée, devant lesquels Nārāyaṇa doit à nouveau confirmer sous serment « tous les mots » qui le composent (face B, 1. 12-17).

Troisième sous-partie (B, l. 17-30). Si les sept mois de procédure de la deuxième partie du texte sont déjà notables, ils ne peuvent lutter avec la lourdeur administrative dont témoigne la troisième. Nārāyaṇa dut en effet présenter à nouveau les faits devant l'assemblée royale en 948 śaka (1026 de notre ère), soit deux ans après s'être acquitté de sa dette. Cette insistance procédurière nous est pourtant précieuse, car ce nouveau témoignage, plus complet que les précédents, nous apporte d'importantes précisions (face B, 1. 17-21). On y apprend en effet que Nārāyaṇa était « à l'origine jeune chanteur » et

10. On notera que dans l'inscription K. 275, face A, st. VI, un dignitaire est autorisé par Sūryavarman Ier à prendre le nom de Narendravarman ( $\mathrm{x}^{\mathrm{e}}$ śaka; ISC, p. 104, p. 109 et n. 7). Malheureusement, il ne s'agit apparemment pas du même dignitaire que dans notre inscription, puisqu'il est associé à un autre toponyme : le Stuk Kak.

11. On rappellera qu'il est bien précisé, en A, 1. 1, que Narendravarman provenait de la commune de Danlān. 
que l'emprunt fut contracté alors qu'il était entré dans la corporation des fabricants de feuilles aux côtés du M. Kh. de Danlān. L'identification de ce Nārāyaṇa au Loñ Las de la deuxième partie est alors inévitable, en supposant que son évolution de carrière l'ait autorisé un jour à prendre un nom sanskrit. Le fait de rapporter, dans la deuxième partie, le procès qu'il avait remporté en 926 śaka pourrait alors avoir eu pour but de légitimer son droit sur les terres qu'il donne en 946 śaka pour rembourser le M. Kh. de Danlān. L'emprunt de Nārāyaṇa était destiné à payer une somme réclamée par le roi ; ne disposant pas de la somme nécessaire pour rembourser, il se résout à donner une terre en contrepartie. Il précise également que cette dette avait été contractée quinze ans avant le remboursement (ou avant la déclaration), soit en 931 (ou 933) śaka.

À la suite de cette déclaration, huit dignitaires se portent garants du fait que cette terre est « vendue » au M. Kh. de Danlān et qu'elle appartenait bien par héritage au Loñ Nārāyaṇa, et ceci « sans contestation » (B, 1. 21-30). Cette condition est manifestement indispensable pour assurer la validité de la transaction. La forme standardisée de ces déclarations accentue encore le caractère administratif de ce texte. Deux d'entre elles apportent toutefois des données supplémentaires. La sixième insiste d'abord sur le fait que la terre en question a été travaillée par Nārāyaṇa ; le fait qu'il ait mis cette terre en valeur est donc apparemment utilisé comme argument pour démontrer sa propriété. Enfin, dans la dernière déclaration, le Loñ 'Āditya témoigne du fait qu'elle avait été donnée par ses ancêtres à ceux de Nārāyaṇa. Il faut sans doute reconnaître dans ce dignitaire le même Loñ 'Āditya qui est présenté dans la première partie comme l'un des membres du Varṇāśrama, également connu comme le Kaṃsteñ Śrī Kṣitīndravarman du sruk de Vāruṇi $(\mathrm{A}, 1.7-8,13)$.

En résumé, l'objet de cette inscription est de confirmer la légitimité de l'autorité exercée par le Loñ Śrīviṣnu et sa famille sur plusieurs propriétés foncières, dont certaines transmises par son père, Narendravarman. Le fait que ce dernier utilise la première personne laisse supposer que cette démarche est au moins en partie réalisée à son initiative.

L'usage du discours direct est assez rare dans l'épigraphie khmère. Ce fait confère déjà au texte un intérêt du point de vue de la documentation de l'ancienne langue khmère. Cet intérêt est encore renforcé d'un point de vue lexicographique par l'utilisation de plusieurs termes ou locutions jusqu'ici imparfaitement comprises ou même inédites qui seront présentées en note (sveñ kāryya, praśañsā, 'amvvok, etc.) ou, lorsqu'elles impliquent de trop longs développements, en commentaire à la fin de cette étude (vamnol, kphvar, spek, etc.).

À cet intérêt philologique s'ajoute l'importance du document du point de vue de l'histoire juridique et administrative du pays khmer. Il existe en effet quelques études de qualité du système juridique de l'ancien Cambodge, notamment celle d'Hubert de Mestier du Bourg (1968), ou portant plus spécifiquement sur les litiges impliqués par la gestion de patrimoines fonciers (Ricklefs $1967^{12}$ ). Il faut également mentionner l'étude de Sachchidanand Sahai, Les institutions politiques et l'organisation administrative du Cambodge ancien, dans laquelle le déroulement des procès ainsi que la composition et les attributions de l'assemblée royale sont présentés (1970, p. 99-111). Pourtant, en la

12. Bien que le titre de cet article ne mentionne que le $\mathrm{x}^{\mathrm{e}}$ siècle de notre ère, il se base également sur des sources du siècle suivant, et donc sur une période couvrant les règnes de Harșavarman I $^{\text {er }}$ à Sūryavarman $\mathrm{I}^{\mathrm{er}}$. 
quasi-absence de nouvelles publications d'inscriptions « juridiques » ${ }^{13}$, ce champ d'études a connu peu de développements depuis quatre décennies. Le texte que nous publions montre clairement dans quelle mesure un seul nouveau document est capable d'affiner notre compréhension de ce sujet, et permet d'ouvrir de nouvelles perspectives.

\section{Conventions}

\section{Dans l'édition :}

$(\ldots)$ : entourent les éléments graphiques à identification visuellement incertaine ; $(\mathrm{a} / \mathrm{o})$ représente ce qui pourrait être lu aussi bien $a$ que $o$.

$[\ldots]$ : entourent des éléments graphiques restitués par conjecture.

$[[\ldots]]$ : entourent les éléments graphiques restaurés par conjecture, n'ayant jamais été écrits.

$\{\mathrm{n}\}$ : entourent un nombre d'éléments graphiques disparus d'environ $n$ akșara.

〈...〉 : entourent des éléments graphiques annulés par le lapicide.

$=:$ réunit des consonnes écrites en ligature mais appartenant à deux mots différents.

$\because$ : virāma.

$\mid:$ danda (ponctuation), à distinguer de $\mathrm{I}=1(\mathrm{II}=2, \mathrm{III}=3$, etc.), lorsque les barres verticales correspondent à des chiffres.

$\mathrm{C}$ : consonne non identifiable.

$\mathrm{V}$ : voyelle non identifiable.

Dans la traduction :

[...] : entourent des éléments ajoutés, sans correspondants directs dans le khmer, mais nécessaires pour satisfaire les exigences de la syntaxe française.

(...) : entourent des explications ou rappels destinés à faciliter la compréhension du texte.

Selon le modèle établi par George Cœdès, nous donnons partout, sauf dans l'édition et dans des citations exactes, les noms d'origine sanskrite en forme normalisée.

\section{Texte}

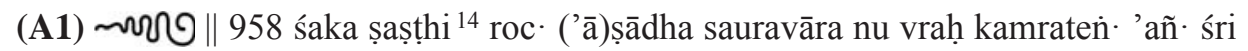

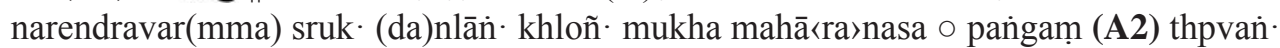
nivedana ta vraḥ pāda kamraten' kaṃtvan ' 'añ 'śri sūryyavarmmadeva $\circ$ man' mān. bhūmi pa(ści)ma \{2\}ra ti duña ta varṇnāśrama cat· sruk· sthā(A3)panā vrah kamraten' 'aña śivalinga ta gi ti 'oy ta loña śriviṣnu nu ten· vija ta kvan· ta varṇna (mahā)nasa sruk· sañvey· svam len’ jā vrah karu(A4)ṇāprasāda kamraten' kaṃtvan· 'aña ta loñ.

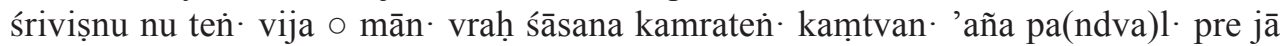
prasāda roḥha 'iști narendravarmma pre sabhā(A5)pati dau sań=gol · praśasta 'oy · jā prasāda 'aña ta śriviṣnu nu vija $\odot$ vraḥ kamraten' 'añ · śri prorthi]vindrapandita sabhāpati

13. Une exception notable est l'inscription K. 1052, dont les faces A et B ont été publiées par Vong Sotheara (2005) sous le numéro Ka 442, et qui présente un parallèle intéressant avec notre texte (cf. infra n. 100). Malheureusement, le contenu de cette inscription est difficile à appréhender en raison de la destruction de la face D et d'une partie des faces A et B.

14. șașthi : la distinction $i / \widehat{\imath}$ ne semble pas être respectée dans cette inscription; on translittérera partout $i$. 
nā 'eka sruka kuti ${ }^{15}$ run’ vrah ka(A6)mraten' 'aña śri rājendrapandita sabhāpati nā do

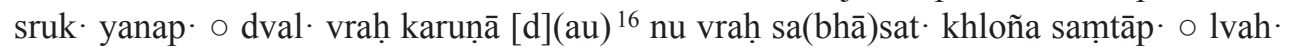
ta gi bhūmi noḥ (A7) pre niyama varṇnāśrama $\circ$ ta lak $\cdot$ bhūmi neḥha tañtyañ $\cdot \circ \operatorname{lo[[\tilde {n}\cdot ]]}$

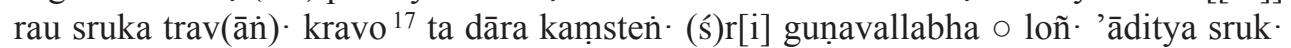

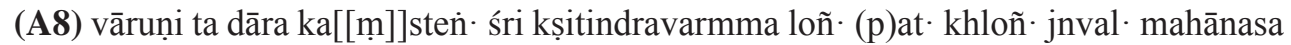

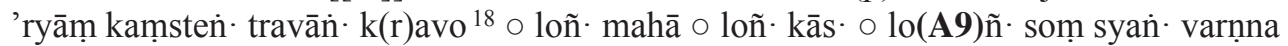
mahānasa sruk · vāruṇi $\circ$ loñ $\cdot$ vin $\cdot \circ$ loñ ' 'yak · ○ loñ kșira varṇna mahānasa (sr)uk ·

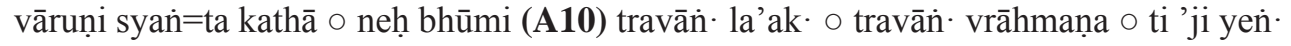
toy· mātṛpakșa $\circ$ dāra prasāda kāla (vra)ḥ pāda parameśvara $\odot$ 'āyatta ta sa(A11)ntāna

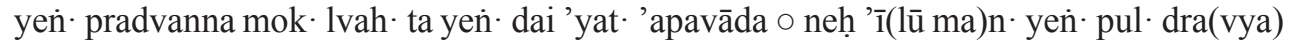
vraḥ kamraten' 'aña śri nare(A12)ndravarmma khloñ · mukha mahānasa sruk· danlān' nu thve vrah rājakāryya pi 'yat· dravya nu yen' son' $\circ(y e)[\dot{n} \cdot]$ ' oy· bhūmi ta (ro)[h](ha)

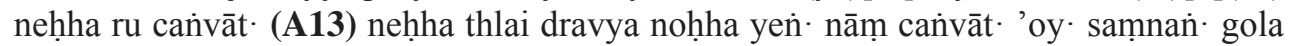
o dravya man· yen· pul· 'añ. ta kaṃsten' vāruni padigah I jyan' 7 guṇa vyara po(A14) $\dot{n} \cdot$ I vrah go II dop· II thnap thpira vlah jrvak I I bhājana II canlyak $(20){ }^{19}$ yau $10 \circ$ srū thlvan' $10 \circ$ 'añ t ta loña kās(a) kryauva I padigah I bhājana I 'añ ta loña (A15) vin· bhājana II $\circ$ 'aña ta loña kṣira bhājana I 'aña ta loña vañ bhājana I 'añ ta loñ soṃ bhājana I 'aña ta loñ' mahā bhājana I srū thlvan̉ 10 (A16) phsama dravya ta jā thlāya bhūmi neh padigah III bhājana 9 canlyak 40 yau 5 ○ srū 20 thlvan' I $\circ$ pon் I kryau I vrah go II dop· II thnap thpira vlah jrvak· I ○ bhūmi runa panto(A17)y· thñāy· śata

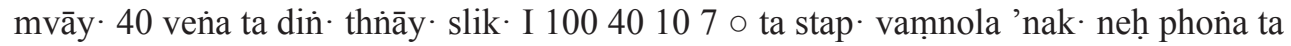
roḥha neḥha vraḥ kamraten' 'añ 'śri prthivindrapa(A18)ndita sabhāpati ${ }^{20}$ nā 'ek· sruk kuti run’ $\odot$ vrah kamraten' 'aña śri rājendrapandita sabhāpati nā do sruk· yanap $\odot$ vraḥ kamraten’ 'añ· śri (ja)ye(A19)ndropakalpa ${ }^{21}$ sabhāsat· nā do sruk· stuk· lvāk• ( $\circ$ vra)ḥ kamratena 'aña śri lakșmandropakalpa ${ }^{22}$ sabhāsat· (n)ā trini sruk· travān’ kuți o kamsten’ (A20) śri lakṣmindropakalpa khloñ· saṃtāp nā 'eka sruk· caṃvañ=vuro $\circ$ kaṃsteń

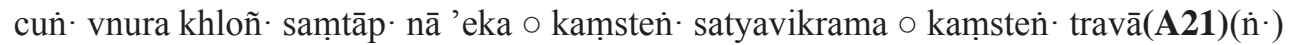

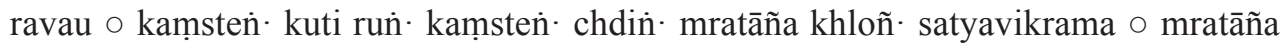
khloñ cun' vnura khloñ $\cdot$ vala satyavikrama sten' slā neḥ (A22) (mū)la vraḥ sabhāpati

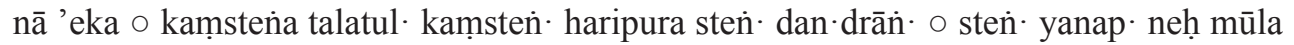
vrah sabhāpati nā do khloña vala gna(A23)(na) mūla vraḥ sabhāpati nā triṇi $\circ$ kaṃsteń cun' vnura khloña bhūtāśa vraḥ ratna $\circ$ kaṃsten' satyavikrama khloñ· gā(p·) patrakāra $\circ$

15. kuti : l'orthographe kuṭi est utilisée à la ligne 19 de la face A ; dans toutes les autres occurrences, l'inscription donne kuti.

16. $[d](a u)$ : seule la partie gauche de la voyelle est encore visible, mais cette restitution nous paraît vraisemblable au vu du contexte, et du fait qu'on retrouve la même séquence ci-dessous (face A, 1. 43) : dval vrah karuṇā dau 'oy' grāmavrddha.

17. kravo : corr. krave. La lecture kravo est certaine, ici comme à la ligne suivante, mais le kamsten . travāin krave (« le Kamsteñ du bassin des crocodiles »), qui est mentionné à la ligne 37 de la face A est sans aucun doute le même dignitaire; cf. également p. 31 .

18. kravo : corr. krave.

19. canlyak 20 yau 10: on pourrait avoir un léger doute sur le chiffre 20, mais le total donné juste dessous (canlyak 40 yau 5) semble confirmer notre lecture ; cf également n. 68.

20. sabhāpati : une éraflure de la pierre dans sabhāpati a provoqué un espace vide entre $s a$ et $b h \bar{a}$.

21. (ja)yendropakalpa: une éraflure de la pierre a provoqué un espace vide avant $n d r o$.

22. lakșmandropa ${ }^{\circ}$ : corr. lakșmindropa ${ }^{\circ}$ (cf. face A, 1. 20). 
(lo)-ña ${ }^{23}$ jeǹ $\cdot\left(\right.$ ga)m mūla (A24) pratihāra 'eka $\circ$ loña janaputra ${ }^{24}$ loña velā mūla pratihāra do $\circ$ loña cān $\cdot$ mūla pratihāra trini $\circ$ loña kañjụ̣ jn(e)in mūla pratihāra catvāri $\odot$ vraḥ (ka)-(A25)mraten' ' aña sabhāpati ta vyara samakṣa nu vraḥ sabhā phon' nu varṇnāśraṃma ta 'ampālla nehha ta lak b būmi o pandvala vrah śāsana ta puruṣap(radh)āna grāma[v]ṛ[ddha] (A26) cās ${ }^{25}$ 'nak=ta jā sākṣi nāṃ vat( $\cdot$ ) sañ=gol · ta bhūmi neḥ ta diśa ta prampiya $\odot$ 'oy· jā vraḥ karuṇāprasāda kamraten' kaṃtvan · 'aña śri sūryyavarmmadeva

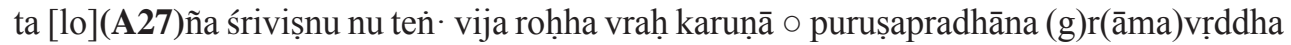
'aṃcāsa 'nak · ta jā sākși o loña vin· daśagrāma ○ loña 'yaka daśagrāma (A28) sruk · vraḥ kāṃ $\circ$ loña sān · sruk · bhāka nakha ta dāra mratāña $(\mathrm{kh})$ loñ $\cdot \circ$ loña ñum sthalāgrāma ta dāra kaṃsten $•$ loña tirtha sruk · vāruṇi $\circ$ loñ je sitā ta (A29) [dāra] m(r)atāña khloña ○ loñ • vraḥ vrai ven’ ta dāra mratā(ña khlo)ñ • o loña 'yak · pādamūla vraḥ hemaśrnigiri ${ }^{26}$

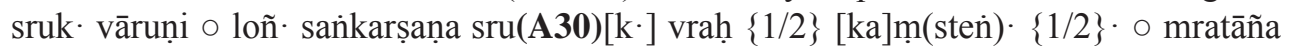
khloñ· devagiri $\circ$ mratāña khloña (te)ṃ 'amuvil mratāña khloñ $(\cdot)$ lāgā $\circ$ mratāña khloñ $\cdot$

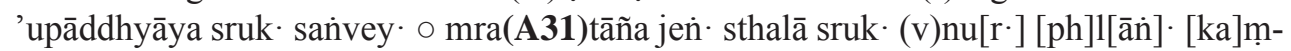

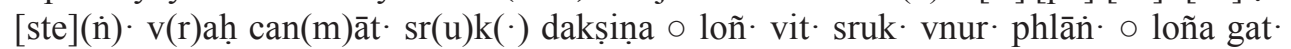

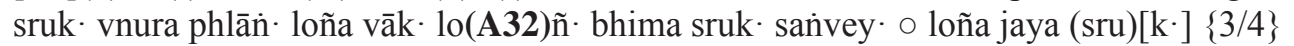
loñ(a) ${ }^{27}$ narā(y') (sruk) (v)nura $\circ[\mathrm{lo}](\tilde{\mathrm{n}}) \cdot \mathrm{sa}(\mathrm{ma})$ (sruk) ( vrah 'u)ra ${ }^{28} \circ$ loña vrahma sruk · lāgā chmara phsaṃ mahānasa 106 ○ (A33) patrakāra khloña vala cāṃ māsa prāk ·

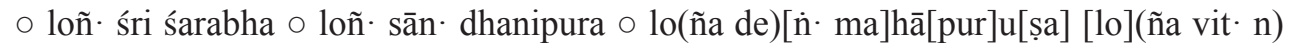
$\operatorname{VCVṃ~}\{10\}^{29}$ (A34) (ro)n் vraḥ dik· loñ r ṛta nam cun' loña 'asa jrai lāna kaṃsten’ pūjā kaṃsten $\cdot \operatorname{kracāl} \cdot \circ \mathrm{ka}(m$ ) steñ $[\cdot]$ stuk $\cdot$ kadamva $\circ$ khloña tāra phtak $(\cdot)$ [khlo]ña vala tẹ̣

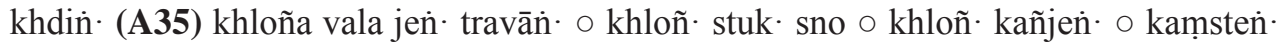
kuti khloña vala puruṣapāla $\circ$ kaṃsten่ thnaai ket $\odot$ kaṃstena vnura tańko $\circ$ kaṃsten் sa(A36)hakāra mratāña khloña tavan· grayān' $\circ$ khloña vala madhurāpura $\circ$ khloña jen’ chdin’ kamsten’ lo khyal ${ }^{30}$ kamsstena karom khyal· o kamsten’ jralon’ loñ· (A37) ’udyāna

23. (lo)ña : l'usage de la forme simplifiée du ña, qui apparaît ici pour la première fois dans notre inscription, y est assez fréquent à partir de la $23^{\mathrm{e}}$ ligne. Le fait qu'ici, il ne soit jamais combiné au virāma pourrait laisser penser que le signe correspond à $\tilde{n}$. Cependant, cette combinaison existe notamment dans les inscriptions K. 1186 (face A, 1. 3, khloñ · estampage EFEO n. 1684) et K. 1253 (1. 12, 'añ. ; estampage EFEO n. 1669). Nous ne distinguerons pas ici les deux allographes de ña.

24. jan $a^{\circ}$ : la pierre est légèrement éraflée au-dessus de l'élément ja ; la lecture jamnna serait également possible, mais ne ferait pas sens.

25. $c \bar{a} s^{*}:$ le début de la ligne n'est pas justifié. Noter que la 1.27 de la face A montre la lecture 'amcāasa dans un contexte identique ; faute de place, le lapicide aura peut-être choisi ici de mettre seulement $c \bar{a}$ dans la marge, et non 'amcā, en notant qu'il avait oublié des akșaras devant $s$.

26. hemaśrnigiri : corr. hemaśrńngagiri.

27. (sru) $[k \cdot]\{3 / 4\}$ loñ $(a)$ : pour être précis, en première ou deuxième position après le $k \cdot$ perdu de $s r u k$, on distingue une ligature à $v$ souscrit et, juste avant le lo de loñ (peut-être séparé de ce mot par un $\circ$ ), un ña dans sa forme simplifiée (cf. n. 23).

28. (vrah 'u)ra: si le vrah paraît assuré, le 'u est en revanche très incertain; il s'agit néanmoins de la moins invraisemblable des hypothèses que nous ayons envisagées.

29. lo(ña de) $[\dot{n} \cdot m a] h \bar{a}[p u r] u[s ̦ a][l o](\tilde{n} a$ vit $\cdot n) V C V \underline{m}\{10\}:$ la cassure horizontale de la pierre a provoqué ici la perte d'un nombre important de caractères; la restitution de [ma]hā [pur]u[șa] peut sembler un peu audacieuse, mais la forme du $u$ de $r u$ est caractéristique pour cette consonne dans cette inscription, et ce qui reste des parties supérieures des autres caractères autorise cette hypothèse (notamment les cheveux du $p u$ et du șa). On notera que le même mot, orthographié mahāpurusa, apparaît dans l'inscription K. 177 au XIII ${ }^{\mathrm{e}}$-XIV' siècle śaka (1. 21, 24, 27 ; IC VII, p. 38).

30. lo khyal : corr. le khyal, « le Sud ». On notera que le dignitaire suivant, également un Kamsten, est qualifié par l'expression karom khyal , « le Nord ». 
○ mratāña khloñ c c(āra) so ○ kaṃsteña devagana $\odot$ sre 'anle I ti pūrvvāgneya noḥ ñyana noḥha runa 4010 ti kaṃsten' travān' krave nu khloña (A38) vala khloña jnvala nu loña veda loña hasa jvan' ta vraḥ kamraten' 'añ śivalinga sruk· narendrālaya $\circ$ len' 'āyatta loñ śrivișnu nu te[n்] · (A39) vija nu santāna neh pradvan· mok · vvam 'āc=ti 'âyatta ta 'nak noḥ ta jvana nu santāna 'naka noḥ ta jvan· ley.

(8) 925 śaka pañcami roc ' 'âśvayu(A40)jya nu cāre vyavahāra 'artha loña lasa kanmyana cammmryana pratyartha loñ· bhima chmāṃ phdaṃ loña ne ta dau nā vraḥ vasana ○ tem śāka bhūmi sruk· sre bhāga kanmyan' (A41) camryan่· nu sre ta prāṃ 'aṃvoka nai camryana ti cāṃ caṃnā(ṃ) ta vraḥ śivalingea rañko liḥ prāṃma mimvāya khe $\circ$ man=mān . vrah karuṇā pi pre mratāñ khloñ bhavakșe(A42)tra dau śodhe thve khpvara nāṃ mok $\circ$ pi kaṃsten' śivapāda sabhāpati nā triṇi cāre 'āya vraḥ $\circ$ sabhā $\circ$ 'arthi ta loña las pratyarthi ta loñ· bhima loña (A43) ne dval · vrạ̣ karunā dau 'oy· grāmavrddha 'aṃcās (')nak pi śodhe thve khpvara roḥ ta vrah karunāa $\circ$ vraḥ sabhā śodhe thve khpvara noḥha vrah karunā (A44) srac· samayuga 'arthi pratyarthi syan=ta nām speka śodhe moka vrah

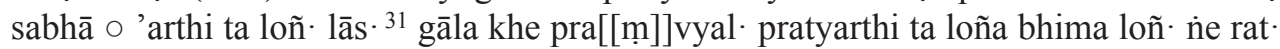
vvaṃ gāl (A45) kaṃsten’ śivapāda sabhāpati nā trini samayuga nu mratãñ k khloñ· śriś(ā)napandita gunadoșa $\circ$ nu mratāña khloña yanap · svat· vraḥ dharmmaśāstra de(A46) p · pandval $\cdot \operatorname{vra}[[\mathrm{h}]]$ śāsana ta loña las $\cdot$ man $\cdot$ gāl $\cdot$ khe pramvyal $\bullet$ pi pratyarthi ta loña bhima loña ne rat khe praṃvyal $\bullet \circ$ pre loña las jnaḥ roḥha vraḥ niya(A47)ma ta 'nau nā

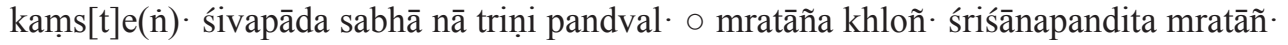
khloñ yanap· smvata vraḥ dharmmaśāstra $\circ$ mratāña (A48) khloñ bhavakșe[t]ra sten๋ bhavanāditya vrạ̣ sabhā ta dai ti 'val.

(8) 946 śaka chatthi ket· karttika candravāra nu 'añ nāṃ loña nārāya(na) ${ }^{32}$ (B1)

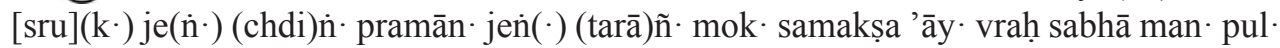
māsa 'aña pāda mvāy' teṃ guṇa vyara langau jyan' mvā(B2)ya teṃ guṇa vyara tanlāp prāk guṇa vyara chnān' kampora prāk $\cdot$ guṇa vyara $\circ \operatorname{lo}\left(\tilde{n}^{\cdot}\right)$ narāyana 'oya sre caṃhura pvāna 'ạ̣voka nu padaḥ (B3) cat[uh] (ś)āla mvāya sn(o)ñ· dravya (ta) roḥha (n)oḥha tí 'aña 'oy· sre noḥ (nu) pada(ḥ) noḥha ta kvan· 'añ ta jmaḥ loña śrivișnu nu 'nak· khlo(B4)

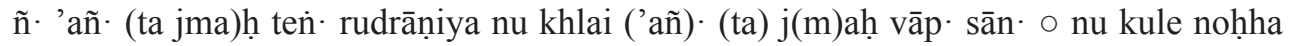
$\mathrm{ph}(\mathrm{o}) \dot{n} \mathrm{a} \circ \mathrm{man}=\mathrm{ti}$ vraḥ sabhā tan் tyān' paṃvyat phona

(๑) 946 (B5) śaka cha[tthi] k(e)ta kartt(i)ka candravāra nu vrah (ka)[mra]t(e)n' 'aña phalappr(i)ya sabhāpati trini $\circ$ kaṃsten· yanap· smvata vrah dharmmaśāstra $\circ$ kaṃste(B6)

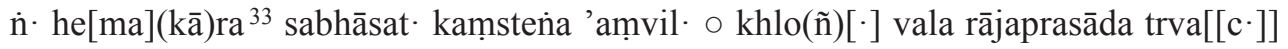
vraḥ ${ }^{34}$ sabhā samayuga pandvala vraḥ śāsana ta loña narāyana $\circ$ man· (B7) sre [no](ḥ) ta pvāna nu catuḥ(ś)āla noḥ ti 'oy' ta mratāñ k khloñ· danlān' thlai māsa noḥ ta pāda vyara nu tanlāp · prāk · ta vyara $\circ$ nu chnān $\cdot$ kaṃ(B8)pora prāk t ta vyara $\circ$ nu langau (j)yan'

31. lās $\cdot$ : ce nom est écrit las $/$ lasa dans toutes les autres occurrences de cette inscription (face A, 1. $40,42,46)$.

32. nārāya (na) : ce nom est écrit narāyana dans toutes les autres occurrences de cette inscription (face B, 1. 2, 6, 8, 10, 12-14, 17-18, 21-30); il faut également noter le nom Narāy (face A, 1. 32), encore plus éloigné de son origine sanskrite.

33. he $[\mathrm{ma}](\mathrm{k} \bar{a}) \mathrm{ra}:$ la lecture est très incertaine; on trouve une occurrence de ce terme dans l'inscription K. 989, face B, 1.13 (930 śaka; IC VII, p. 176).

34. trva[[c·]] vrah : restitution de $c \cdot$ proposée par Ph. N. Jenner. Il y a un espace entre les akșara trva et $v r a$, qui plus est dans une portion de la pierre qui a été éraflée plus ou moins superficiellement. On pourra expliquer cet espace en supposant l'éraflure d'un signe de ponctuation originel, ou en supposant que le lapicide a laissé cet espace ouvert à cause des éléments souscrits de l'akșara ppri de la ligne précédente. Quoi qu'il en soit, l'espace disponible est trop petit pour accueillir l'akșara $c \cdot$ manquant. 


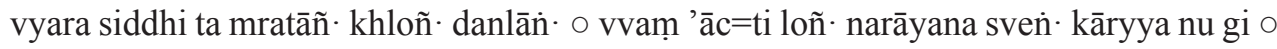
nā mratāña khloña (B9) (da)nlān · (d)ai (si)ddhi bhūmi noḥha vāpa sāna dai nu ku(le) ta roḥha noḥha (ma)n· noḥ ti mratāñ · khloñ danlān’ duña pi 'oy· siddhi roḥha ta praśa(B10) ṅsā mratāñ $(\cdot k h l o) \tilde{n} \cdot$ danlāna $\circ$ man=ti nāma prasira c(ā)re neh mok=ta vrạ̣ kamraten' 'añ' kuti run' sabhāpati nā 'eka $\{1\}^{35}$ loñ narāyana (pa)ṃvyat • $\circ$ (man·) (B11) [ro]

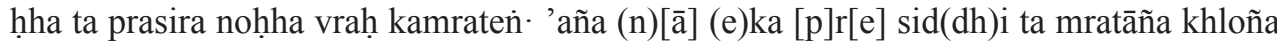

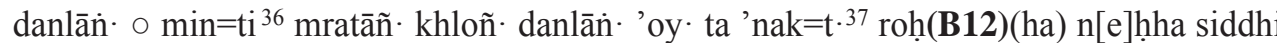
ta 'naka ta roḥha $\circ$ man=ti 'añ nu 1(oñ.) (na)rā(yana) nāṃ prasira ta roḥha neḥh mok=ta vraḥ kamraten' 'añ v ven· jen' sabhā(B13)pati catvāri o vraḥ kamraten' 'aña tan்[[·]]tyan் loña (na)rā(ya)na paṃvyat $\operatorname{sap}(\cdot)$ pada man· roḥ ta prasira neḥha vraḥ kamraten' 'aña ven· jen' (B14) (sa)bhāpati catvāri samayuga nu kaṃstena kaden' smva(t·) vrạ̣ dharmmaśāstra $\operatorname{kam}(\mathrm{s}) \operatorname{ten}(\cdot)$ 'aśvapattana kaṃsten̉ v vrạ 'aśrama $\circ$ man· loña narāyana

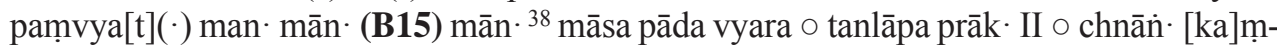
p(o)ra prāka II langau jyan’ II ti pula pi 'oy· sre noḥ ta pvāna nu catuhśāla noḥha ta (mvā)(B16)ya siddhi ta mratāña khloña danlāñ • ○ man· sre no[hḥa ca]t[u](ḥsāla) noḥha ti mratāña khloña danlāna 'oy· ta kvan· ta jmạ̣ loñ śrivișna ${ }^{39}$ nu 'me k(u)(B17)le neh phon' siddhi (ta) 'nak· ta roḥha nẹ̣(ha) \|

(8) (9) $48^{40}$ śaka 'așțami ket· vaiśâka nu vrah sabhā tañtyan’ loña narāyana $\circ$ kathā (B18) loña narāyana ta kanmyaña camryan’ teṃ dau nā varṇna p(a)[trak]āra mvāya mūla

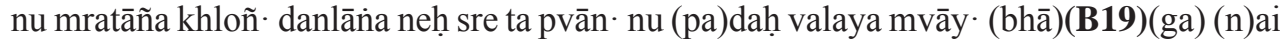

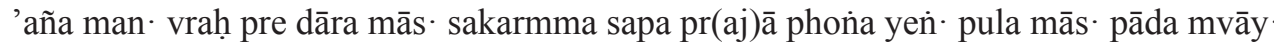
tanlāp · prāk · mvāya chnān’ ka[[ṃ]]pora mvāya lañgau (B20) j(y)aña I ti mratāña khloña danlān' 'oya (rāja)kāryya nu gi guṇa dravya ta roḥha noḥ 'yat=pi 'oya 'aña yok' sre nọ̣ nu valaya padaḥ no[h] (B21) 'aña 'oya thlai dravya mratāña khlo(ñn') danlān' mā(n·) jā prā(ṃ) dantapa chnāṃ $\circ$ kathā khloña vala kaṃven’ bhūmi neh ${ }^{41}$ ti loña narāyana laka ta (mra)(B22)(tā)ña khloña danlāña bhūmi loña narāya(na) 'aṃvi ta sa(nt)āna vvaṃ tela māna vāda $\circ$ kathā mratāña khloña ta mūla ta kanmvaya kaṃsten̉ bhavanāditya (B23) bhūmi noh (ti lo)ña narāya(na) lak=ta mratāña khloña danlāna bhūmi loña narāyana 'aṃvi ta santāna loña narāyana vvaṃ tela mān · vāda o kathā (B24) (lo)ña 'yak · 'ugrāvāsa grāmavṛddha $\odot$ bhūmi noḥ ti loña narāyana lak=ta mratãña khloña danlān $\cdot$ bhūmi loñ narāyana 'aṃvi ta santāna vvaṃ [te](B25)la (m)ān· vāda 'apavāda $\circ$ kathā khloña vala daśagrāma śivagandha bhūmi noḥ ti loña narāyana lak=ta mratāña khloñ danlān $\cdot$ bhūmi lo[ñ · (B26) narāyana 'ạ̣vi ta santāna vvaṃ tela māna vāda $\circ$ kathā lo(ña) grāmavṛddha gandharvva bhūmi neh ${ }^{42}$ ti loña narāyana lak=ta mratāña khloña danlāna bhūmi lo(ña)

35. $\{1\}$ : vraisemblablement une ponctuation de type $\odot$.

36. $\min =t i$ : corr. $\operatorname{man}=t i$.

37. 'nak=t. : corr. 'nak=ta; on retrouve cette orthographe à plusieurs reprises dans l'inscription K. 1186 (jvan $=t$, face B, 1. 6, 12, par exemple). Le viräma y semble étrangement concerner la première consonne et non la souscrite. Il faut alors sans doute lire 'nak $=t a$ et $j v a n \cdot=t a$.

38. $m \bar{a} n \cdot(15) m \bar{a} n \cdot:$ le deuxième $m \bar{a} n \cdot$ est vraisemblablement repris ici par dittographie.

39. śrivisna : le texte porte ici sans nul doute śrivișna. Dans l'impossibilité de vérifier nos lectures sur la pierre, il nous faut accepter un certain nombre de cas où le doute entre śriviṣnu et śriviṣna est permis.

40. 8) (9)48: l'espace disponible entre le fleuron et le 9 pourrait suggérer la présence d'un deuxième double danda. Par ailleurs, la moitié gauche du 9 a disparu dans l'éclat vertical présent sur l'essentiel de la stèle.

41. neh : corr. noh.

42. neh : corr. noh. On notera que l'on rencontre la même confusion e/o dans le cas de kravo/krave et de lo khyal/le khyal (cf. n. 17, 18 et 30). 
(B27) narāyana vvaṃ tela māna vāda $\circ$ kathā mra(t)āña khloñ caṃ[v]yara bhūmi noḥ bhūmi loñ narāyana ti loña narāyana thve 'ven' hona ti 'aña tyaña 'ukka $\circ$ [kathā] (B28) loña vraḥ vnura 'aṃvi bhūmi noḥ ti loña narāyana lak=ta mratāña khloñ danlān · bhūmi loña narāyana 'amvi ta santāna vvam tela māna vāda [o kathā lo](B29)ñ. ta mūla ta jmaḥ loña 'āditya (bhū) $[\mathrm{m}] \mathrm{i}[\mathrm{no}]$ ḥha man' loñ( $\cdot$ ) narāyana lak=ta mratāña khloña danlān' bhūmi loña narāya[na] ti ('ji) 'aña 'oy' ta $\{2 / 3\}^{43}$ (B30) loña narāyana siddhi ta loña narā[yana]

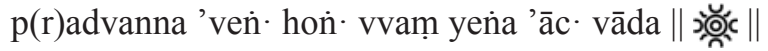

\section{Traduction}

(A1-4) En 958 śaka, sixième [jour] ${ }^{44}$ de la quinzaine sombre d'āṣāạha, un samedi, le Vraḥ Kamrateñ 'Añ Śrī Narendravarman du sruk de Danlān, chef principal des cuisiniers, informa humblement Sa Majesté par succession matrilinéaire ${ }^{45}$ Śrī Sūryavarmadeva : il y a une terre à l'ouest ...ra, achetée $(d u \tilde{n})^{46}$ aux membres du Varṇāśrama ${ }^{47}$, où ( $t a$ gi $)$ a été fondé un sruk ${ }^{48}$ [et] installé le V. K. 'A. Śivalinga. Elle a été donnée ('oy) au Loñ Śrīviṣnu et à la Ten Vija, [mes] enfants ${ }^{49}$, de la corporation des cuisiniers du sruk de Sañvey. [Je] (Narendravarman) demande que [cette terre] constitue une faveur royale ${ }^{50}$ de S. M. par succession matrilinéaire au bénéfice du Loñ Śrīviṣnu et de la Ten Vija.

(A4-5) Il y eut un édit royal de S. M. par succession matrilinéaire, transmettant l'ordre qu'elle constitue une faveur conformément à la requête de Narendravarman [et] ordonnant à des présidents de l'assemblée (royale) ${ }^{51}$ d'aller ériger des bornes [et] une

43. $\{2 / 3\}$ : on présume que cette lacune pourrait être comblée par un mot tel que kule ou santāna.

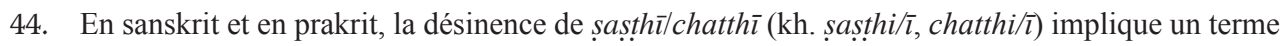
féminin. On attendrait donc plutôt le mot tithi, qui peut être féminin, que l'un des termes désignant « le jour (civil) », généralement non féminins. Sur l'importance de la distinction entre jour lunaire et civil, voir Eade 2008, p. 80-81. Dans notre cas, J. C. Eade a considéré qu'il s'agit du jour civil. Cette date correspondrait alors au vendredi (et non samedi !) 18 juin 1036 de notre ère (Billard \& Eade 2006, p. 416).

45. Cf. infra commentaire, p. 54. Nous rappelons que la présentation de commentaires en fin d'article n'a d'autre raison que la volonté d'éviter de longs développements en bas de page.

46. Saveros Pou glose duñ par : «Acheter, s'acquérir qqch» (2004, s.v, p. 252a). Il s'agit ici d'un remboursement pour dette et non d'un achat proprement dit (cf. face A, 1. 11-17). La même observation vaut mutatis mutandis dans le cas de lak, « vendre », à la ligne A, 7 et encore de duñ à la ligne $\mathrm{B}, 9$.

47. Cf. infra commentaire, p. 54-55.

48. Vraisemblablement le sruk narendrālaya de la ligne 38 de la face A.

49. Cf. l'expression plus complète ta kvan 'añ ta jmaḥ loña śrivișnu dans B, 1. 3.

50. Une expression équivalente à svam lè jā vrah karuṇāprasāda se trouve dans l'inscription K. 598 : noh gi pi mratā̃n kh[lo] ñ svam lè̃ jā vrah dāna pi jvan ta vrah 'āy vrai karañ, «C'est cette [terre] dont le Mratāñ Khloñ a demandé qu'elle constitue un don royal, pour l'offrir au dieu de Vrai Karan் » (face B, 1. 7-8; 928 śaka; Finot 1928, p. 67 et NIC II-III, p. 231). La notion de confirmation royale de transfert de propriété foncière a déjà été présentée par ailleurs (Ricklefs 1967, p. 413, 415); elle s'exprime aussi en sanskrit dans des inscriptions contemporaines de la nôtre, comme dans la stance XXIX de l'inscription K. 1198 ( $\mathrm{x}^{\mathrm{e}}$ śaka; partie sanskrite inédite) : hemarūpyādibhir dravyaih krītvā kṣmām kṣetrasamyutām drậīkartum sa rājānam punas tām samayācata, «Ayant acheté, au moyen de biens consistant en or, argent, etc., une terre pourvue de rizières, il la demanda de nouveau au roi, pour confirmation (ou : demanda encore au roi de la confirmer) »; voir aussi K. 158, st. XVII : pāramparyyaprasiddhyaitā bhümih [corr. bhümīh] krītvāpi yuktitah yaś śrīrājendravarmmānạn yayāce bhüpatim punaḥ, « ayant acheté ces terres de façon régulière, avec des titres de propriété sans lacune, il les demanda ensuite au roi Rājendravarman » (925 śaka; IC II, p. 100, 107).

51. Śrī Prọthivīndrapaṇdita et Śrī Rājendrapaṇdita (face A, 1. 5-6). 
(la présente ?) inscription ${ }^{52}$ qui fasse de ('oy jā [la terre] Sa ('añ) faveur au bénéfice de Śrīviṣnu et de Vija ${ }^{53}$.

(A5-7) Le V. K. 'A. Śrī Prthivīndrapandita, président de l'assemblée de premier rang, du sruk de Kuți Ruñ ${ }^{54}$ [et] le V. K. 'A. Śrī Rājendrapaṇịta, président de l'assemblée de second rang, du sruk de Yanap reçurent humblement l'ordre [émis] par grâce royale, se rendirent avec des assesseurs de l'assemblée royale [et] des Khloñ Saṃtāp ${ }^{55}$ à ladite terre, transmirent l'injonction (pre niyama) [aux] membres du Varṇāśrama qui ont vendu (lak) cette terre [et] enquêtèrent.

(A7-9) Le Loñ Rau du sruk de Travān Krave, qui avait reçu [le titre de] ${ }^{56}$ Kaṃsteń Śrī Guṇavallabha ; le Loñ 'Āditya du sruk de Vāruṇi, qui avait reçu [le titre de] Kạ̣steñ Śrī Kṣitīndravarman ; le Loñ Pat, Khloñ Jnval ${ }^{57}$ des cuisiniers, frère aîné du Kaṃsteñ de Travān Krave ; le Loñ Mahā, le Loñ Kās, le Loñ Soṃ, tous (trois) de la corporation des cuisiniers du sruk de Vāruṇi ; le Loñ Vin ; le Loñ 'Yak ${ }^{58}$; le Loñ Kṣira de la corporation des cuisiniers du sruk de Vāruni ; tous ceux-là déclarèrent :

(A9-11) Voici les terres de Travān La'ak [et] de Travān Brāhmaṇa reçues par nos ancêtres en ligne maternelle par faveur (royale) à l'époque de S. M. Parameśvara (Jaya-

\section{Cf. infra commentaire, p. 55.}

53. Pour notre interprétation de la fin de la phrase, et surtout du mot 'añ comme abréviation de kamraten kaṃtvan 'añ, voir face A, 1. 26. Nous ne voyons pas de possibilité pour faire coordonner la personne dénotée par ce 'añ avec celle que le même pronom dénote à partir de $\mathrm{A}, 1.48$ et surtout sur la face B de la stèle. Il faut alors remarquer que le fait que les éléments loñ ou ten் n'apparaissent pas non plus devant les noms propres renforce l'impression abrégée de ce passage.

54. Le même dignitaire apparaît dans l'inscription K. 380 O, provenant du temple de Preah Vihear (1. $32 ; \mathrm{x}^{\mathrm{e}}$ śaka; IC VI, p. 261). Nous avons trouvé le toponyme Kuți Run dans quatre autres inscriptions. Un loñ kuti ruñ apparaît dans K. $221 \mathrm{~N}\left(1.13\right.$; $\mathrm{x}^{\mathrm{e}}$ śaka ; province de Banteay Mean Chey ; IC III, p. 58), un personnage nommé vrah kuti run் dans K. 521 N (1. 7 ; xe śaka; province de Siem Reap ; IC IV, p. 168) ; un sruk kuḍi run est donné à un dieu dans l'inscription K. 873 (1. 9 ; 843 śaka; province de Siem Reap ; IC V, p. 104) ; et un Vrạ̣ Kạ̣sten Kuti Run, président de l'assemblée de quatrième rang, apparaît dans K. 1198 (face B, 1. 2 ; x śaka ; Samrong, province d'Oudor Mean Chey ; NIC II-III, p. 242). Les lieux de provenance de ces inscriptions sont assez dispersés et ne donnent donc aucune indication sur la localisation de la commune de Kuṭi Run.

55. Le terme saṃtāp, dérivé de stap « écouter », implique que les khloñ saṃtāp seraient chargés d'écouter ; l'expression stap vamnol (face A, 1. 17) précise qu'il s'agit d'écouter les dépositions. Ces fonctionnaires n'étant pas les seuls à écouter lesdites dépositions, on peut supposer qu'il s'agissait plus précisément de les enregistrer. On proposera alors de les considérer comme les « greffiers » de l'assemblée royale. Les noms des deux assesseurs et des deux greffiers concernés par cette affaire sont donnés aux lignes 18 à 20 de la face $\mathrm{A}$.

56. La formule normale semble être dār jmah / dār nāma + titre (par ex. K. 782, piédroit nord, 1. 3-4 ; 993 saka ; IC I, p. 224), dont notre inscription présenterait une version abrégée.

57. On retrouve probablement ce Khloñ Jnval à la ligne 38 de la face A. Il est difficile de préciser quelle était la fonction de ce « Khloñ Jnval des cuisiniers ». En effet, le terme jnval a toujours posé des problèmes d'interprétation ; George Cœedès a supposé qu'il correspond au khmer moderne « čûol, "louer, prendre à gages" ", en ajoutant que «nãk čhnûol, kón čhnûol ont le sens de "serviteur à gages, salarié" » (IC III, p. 14 n. 1). En revanche, Saveros Pou a proposé une autre connexion étymologique possible avec le vieux javanais juwal et le malais moderne jual « vendre » (2004, s.v., p. 193). Quoi qu'il en soit, on ne peut pour l'instant qu'attendre d'en connaître un équivalent sanskrit, comme le soulignait Cœdès, ou au moins des occurrences plus explicites. À propos de cette fonction, voir également la note de Cœdès dans le cas de l'inscription K. 913, 1. 10 (xe śaka ; IC V, p. 271 n. 4).

58. Ce Loñ est le seul de cette liste à ne pas être impliqué dans les transactions qui vont suivre (cf. n. 67 et 90). 
varman II) ${ }^{59}$. Elles relèvent de l'autorité de notre famille depuis lors ${ }^{60}$, jusqu'à nous tous (yen dai) ${ }^{61}$, sans contestation.

(A11-12) Voici [la situation] maintenant : nous avons emprunté avec intérêt des biens [au] V. K. 'A. Śrī Narendravarman, chef principal des cuisiniers, du sruk de Danlāṅ, pour accomplir le service royal ${ }^{62}$. Afin que, à défaut de biens, nous remboursions ${ }^{63}$, nous avons donné la terre ${ }^{64}$ telle qu'elle a été délimitée.

(A13) Voici la valeur de ces biens. Nous avons fait la délimitation et fait ériger ('oy samnnaì) les bornes.

(A13-15) Biens que nous avons empruntés avec intérêt :

- moi, le Kaṃsten de Vāruṇi : 1 crachoir de 7 jyan், deux fois (pour intérêt) ${ }^{65}, 1$ [vache] pleine, 2 vaches sacrées, 2 pagnes (dop), (un) vlah d'étoffes cousues ${ }^{66}, 1$ porc, 2 plats, 20 canlyak de 10 yau, 10 thlvan de paddy ;

- moi, le Loñ Kās : 1 [bœuf] châtré, 1 crachoir, 1 plat ;

- moi, le Loñ Vin : 2 plats ;

- moi, le Loñ Kșīra : 1 plat;

- moi, le Loñ Vañ : 1 plat;

- moi, le Loñ Soṃ : 1 plat ;

- moi, le Loñ Mahā : 1 plat, 10 thlvain de paddy ${ }^{67}$.

59. Le fait de se reporter au règne de Jayavarman II pour des biens fonciers et des fonctions est un phénomène récurrent qui ne correspond pas forcément à une réalité historique, mais pourrait s'expliquer par une volonté de légitimation. Cf. l'observation de George Coedès (IC VII, p. 129) : « Pour l'épigraphie angkorienne qui commence en fait avec le règne d'Indravarman en 877, ceux de Jayavarman II et de son fils dont on n'a pas encore trouvé d'inscription constituent une époque semi-légendaire, à laquelle les grandes familles religieuses font remonter l'origine de leur sacerdoce, et les propriétaires de biens fonciers l'origine de leurs titres de propriétés. »

60. Sur la séquence pradvanna mok, voir Sak-Humphry 2005, p. 223 s.v. pradvanna, mais aussi p. 229 s.v. mok. La séquence vient en fin de phrase, comme le montre le contexte de K. 693, face A 1.15 (925 śaka; IC V, p. 204) ; on pourrait penser à une traduction telle «à long terme » ou " durablement » (cf. face B, 1. 30 pradvan 'veñ « depuis longtemps »). Mais nous ne voyons pas comment échapper au sens « depuis » pour pradvan.

61. Notre traduction « nous tous » pour yen dai est une pure spéculation. Le sens littéral devrait être «nous autres », ce qui ne semble pas convenir au contexte. Philip N. Jenner (comm. pers.) nous propose « ourselves », ce qu'il estime « no more than a relaxed equivalent» du sens littéral.

62. L'expression thve vrah rājakāryya apparaît également dans l'inscription K. 257, piédroit nord, 1. 22 ( $\mathrm{x}^{\mathrm{e}}$ śaka) ; Cœdès traduisait : « pour faire le service royal », et notait : " sans doute "payer l'impôt" ou "racheter les corvées" » (IC IV, p. 150, n. 1). À ce sujet, voir Sahai 1970, p. 114-115, 118 (où, à plusieurs reprises, l'auteur orthographie fautivement ce composé räjyakārya). Qu'il s'agisse d'un impôt proprement dit ou de corvées, l'idée est toujours d'assurer un service pour le roi.

63. Pour un autre cas de remboursement d'un bien par un autre, voir K. 257, piédroit sud, 1. 34 ( $\mathrm{x}^{\mathrm{e}}$ śaka ; IC IV, p. 143, 147) man 'yat tammrya nu soń tammrya kaṃsten்n 'oy bhümi : « [...] qui n'avait pas d'éléphant à rendre en remplacement des éléphants du Kamstend, donna la terre [...] » et K. 257, piédroit nord, 1.7 ( $\mathrm{x}^{\mathrm{e}}$ śaka; IC IV, p. 144, 149) 'yat dravya « à défaut de biens » (pour rembourser une dette).

64. Il s'agit probablement de la première des deux terres mentionnées aux lignes A, 9-10, c'est-à-dire celle de Travān La'ak. Pour la deuxième, voir la note 88.

65. Cf. infra commentaire, p. 55-56.

66. Cf. infra commentaire, p. 56.

67. Le Kaṃsteñ de Vāruṇi est probablement le Loñ ’Āditya qui est mentionné aux lignes A, 7 et B, 29. On notera que le Loñ Vañ est le seul de ces sept débiteurs à ne pas apparaître parmi les membres du Varnāāsrama mentionnés aux lignes A, 7-9. 
(A16-17) Total des biens correspondant à la valeur de cette terre : 3 crachoirs, 9 plats, 40 canlyak de 5 yau $^{68}, 20$ thvlain de paddy ${ }^{69}, 1$ [vache] pleine, 1 [bœuf] châtré, 2 vaches sacrées $^{70}, 2$ pagnes, (un) vlah d'étoffes cousues, 1 porc. La terre est large d'est en ouest de 140 [unités] et longue de 557 [unités] du nord au sud ${ }^{71}$.

(A17-24) Ont écouté ladite déposition (vamnola) ${ }^{72}$ de ces personnes (les débiteurs, membres du Varnāásrama : face A, 1. 13-15) :

- le V. K. 'A. Śrī Prthivīndrapaṇdita, président de l'assemblée de premier rang, du sruk de Kuṭi Run ;

- le V. K. 'A. Śrī Rājendrapaṇ̣ita, président de l'assemblée de second rang, du sruk de Yanap ;

- le V. K. 'A. Śrī Jayendropakalpa, assesseur de l'assemblée de second rang, du sruk de Stuk Lvāk ;

- le V. K.'A. Śrī Lakșmīndropakalpa, assesseur de l'assemblée de troisième rang, du sruk de Travāñ Kuți ;

- le Kaṃsteñ Śrī Lakṣmīndropakalpa, Khloñ Saṃtāp de premier rang, du sruk de Caṃvañ Vuro ${ }^{73}$;

- le Kạ̣steñ de Cuñ Vnur, Khloñ Saṃtāp de premier rang ;

- le Kamısten (de ?) ${ }^{74}$ Satyavikrama ;

68. Le mot canlyak désigne un "vêtement recouvrant le corps des hanches vers le bas » (Pou 2004, s.v., p. 157). On notera qu'un seul débiteur en a emprunté à raison de canlyak 20 yau 10, alors que le total est donné ici par canlyak 40 yau 5 . En faisant le parallèle avec notre interprétation de $s r \bar{u} 20$ thlvain I (cf. la note suivante), il y aurait alors $20 \times 10=40 \times 5=200$ yau de canlyak. Ces formulations auraient encore une fois le mérite de distinguer $20+10$ de $20 \times 10$ et $40 \times 5$ de $40+5$. Cependant, il est surprenant que le chiffre 200 n'ait pas été utilisé ici. On préférera donc traduire par « 20 canlyak de 10 yau » et " 40 canlyak de 5 yau ». Quoi qu'il en soit, les biens remboursés sont équivalents en quantité, bien qu'ils soient présentés sous une autre forme. Il est naturellement possible que ces vêtements ne soient pas de longueur uniforme, mais le fait que leur taille passe du simple au double laisse plutôt supposer qu'il ne s'agit pas de canlyak proprement dit, mais plutôt d'étoffe pour les fabriquer.

69. Les débiteurs ont emprunté deux fois srü thlvan 10, soit « 20 thlvaì de paddy », en tout. Or, dans le total noté ici, on a srü 20 thlvañ I. A priori, on devrait traduire par « 1 thlvan de 20 paddy », ce qui n'a aucun sens : on attendrait plutôt srū thlvain 20, « 20 thlvain de paddy », pour que le total soit exact. On peut alors supposer que le fait d'écrire 20 thlvan $I$ au lieu de thlvan் 20 I évite tout simplement la confusion entre $20 \times 1$ et $20+1$. Cette formulation n'en reste pas moins inattendue; on ne peut que supposer qu'elle permettait d'insister sur le fait que « $\mathbf{1}$ [quantité totale] de 20 thlvañ de paddy » était due au total.

70. Le regroupement des biens dans le total permet de supposer que poin, kryau et vrah go ne sont pas associés par hasard et donc que les termes poí et kryau qualifient bien des bovins : une vache pleine et un bœuf châtré.

71. Cf. infra commentaire, p. 57.

72. Cf. infra commentaire, p. 57-58.

73. Les deux éléments du toponyme camvañ vuro sont rares ou même insolites. Camvvan est peutêtre dérivé de con் (Pou 2004, s.v., p. 167-168 : «Lier. Bâtir en brique ou pierre. Établir, accomplir »), ce qui pourrait donner le sens de «bâtiment »; pour l'autre élément, cf. le sruk candoǹ vuro pramān śreșthapura dans K. 337, face A 1. 5 (815 śaka; estampage BnF 110 (13) = 1. 4 dans NIC II-III, p. 87).

74. Lorsque nous ne disposons pas d'occurrences dans d'autres inscriptions, comme c'est le cas pour satyavikrama, il peut être difficile de décider s'il s'agit d'un toponyme ou d'un anthroponyme. La structure du sanskrit satyavikrama correspond à première vue à celle d'un anthroponyme. Pourtant, le fait qu'on aurait alors trois fonctionnaires portant le même nom (voir infra) incite à rester prudent. On adoptera donc la notation «(de?) », sauf dans des cas évidents tels Haripura. 
- le Kaṃsteñ de Travān Ravau ${ }^{75}$;

- le Kamsteñ de Kuṭi Run் ;

- le Kaṃsten் de Chdin் ;

- le M. Kh. (de ?) Satyavikrama ;

- le M. Kh. de Cun Vnur;

- le chef militaire (de ?) Satyavikrama ;

- le Sten் (de ?) Slā : ce dernier, responsable ${ }^{76}$ des présidents de l'assemblée royale de premier rang;

- le Kamsten் (de ?) Talatul ;

- le Kạ̣sten de Haripura ;

- le Steñ de Dandrān் ${ }^{77}$;

- le Sten் de Yanap : ce dernier, responsable des présidents de l'assemblée royale de second rang;

- le chef militaire (de ?) Gnan, responsable des présidents de l'assemblée royale de troisième rang ;

- le Kaṃsteñ de Cun Vnur, Khloñ Bhūtāśa des joyaux royaux ${ }^{78}$;

- le Kaṃsten் (de ?) Satyavikrama, Khloñ Gāp des fabricants de feuilles ;

- le Loñ Jen் Gaṃ, responsable des gardiens de porte de premier rang ;

- le Loñ Janaputra [et] le Loñ Velā, responsable(s) des gardiens de porte de second rang ;

- le Loñ Cān, responsable des gardiens de porte de troisième rang ;

- le Loñ Kañjuh Jnen், responsable des gardiens de porte de quatrième rang.

(A24-27) Les deux V. K. 'A. présidents de l'assemblée (Prothivīndrapaṇita et Rājendrapaṇdita, 1. 17-18), en présence de toute l'assemblée royale ${ }^{79}$ et de l'ensemble de ce Varnāśrama qui a vendu la terre, ont transmis aux notables (puruṣapradhāna), aux anciens de la commune ( $r$ rāmavrddha) et aux propriétaires terriens (cās 'nak) ${ }^{80}$, qui

75. Le rapprochement s'impose avec le toponyme travāin rvvau dans K. 690, piédroit nord, 1.28 et $30\left(\mathrm{IX}^{\mathrm{e}}-\mathrm{X}^{\mathrm{e}}\right.$ śaka; IC VII, p. 92), dont Cœdès avait déjà remarqué qu'il n'était manifestement autre que l'actuel Trapéang Ropou d'où provient cette inscription. Ce temple, qui a fait l'objet d'un diagnostic archéologique en 2005, est situé à proximité de l'aéroport de Siem Reap (IK 518, Lunet de Lajonquière 1911, p. 132 ; Bâty 2005).

76. Traduction conjecturale de mūla (cf. Sahai 1970, p. 114, n. 5, 6).

77. Variante du nom dàndrāñ qui est bien attesté dans des toponymes. Cf. sruk chok dàndrāin « la commune du bosquet de dandrān் » K. 292, H, 1.13 (933 śaka; IC III, p. 216) ; K. 467, 1. 13, 16 (933 śaka; IC III, p. 218). Le terme dañdrā̀n désigne une « herbe des lieux inondés, Polygonum barbatum (Polygon.)» (Pou 2004, s.v., p. 244).

78. Cf. infra commentaire, p. 58-59.

79. Rien ne permet malheureusement de préciser si cette assemblée est une autorité centrale ou l'une des assemblées régionales attestées dans les inscriptions (de Mestier du Bourg 1968, p. 41). Quoi qu'il en soit, on notera que dans les cas de confirmation de propriété comme dans ceux de litiges fonciers, les verdicts de cette assemblée sont considérés comme des décisions du roi (face A, 1. 27, 47).

80. À propos des trois catégories de témoins, purușapradhāna, grāmavrddha et cās 'nak, voir Sahai 1970, p. 84 et suiv. avec n. 7 ; voir aussi NIC II-III, p. 229 n. 12. Pour ce qui concerne la distinction entre cās 'nak (ou 'amcās / 'cās 'nak), littéralement " personne âgée », et grāmavrddha, " ancien du village », Cœedès note : « J'ignore en quoi amcas dérivé de ${ }^{a}$ cas "vieux" est différent de grāmavrddha. Peut-être le mot a-t-il déjà son sens moderne de "maître" et désigne-t-il les propriétaires de ces deux villages » (IC V, p. 141, n. 2). Il faut noter que l'hypothèse de Cœdès se fonde sur l'utilisation d'un dérivé ('ancas) de 'cas. Dans notre inscription on rencontre à la fois le dérivé et la forme simple, mais l'usage de 'cās à la ligne A, 26 est peut-être lié à un manque de place (cf. n. 25). 
furent témoins de la délimitation des périmètres (nām vat $)^{81}$ et de l'érection des bornes de cette terre aux huit points cardinaux, l'édit royal faisant de ('oy jă [cette terre] une faveur royale de S. M. par succession matrilinéaire Śrī Sūryavarmadeva au Loñ Śrīviṣnu et à la Ten Vija, par grâce royale.

(A27-37) Notables, anciens de la commune et propriétaires terriens, qui furent témoins :

- le Loñ Vin [chef] de dix villages ${ }^{82}$;

- le Loñ 'Yak [chef] de dix communes, du sruk de Vrạ Kāṃ ;

- le Loñ Sān du sruk de Bhāka Nakha qui avait reçu [le titre de] Mratāñ Khloñ ;

- le Loñ Ñum de Sthalāgrāma qui avait reçu [le titre de] Kaṃsteñ ;

- le Loñ Tīrtha du sruk de Vāruṇi ;

- le Loñ Je Sitā qui avait reçu [le titre de] Mratāñ Khloñ ;

- le Loñ Vrah de Vrai Veñ qui avait reçu [le titre de] Mratāñ Khloñ ;

- le Loñ 'Yak, Pādamūla du Hemaśrnngagiri ${ }^{83}$, du sruk de Vāruṇi ;

- le Loñ Sańkarșaṇa du sruk de Vrạ̣ ... Kaṃsten ;

- le M. Kh. de Devagiri ;

- le M. Kh. de Teṃ 'Aṃvil ;

- le M. Kh. de Lāgā ;

- le M. Kh., professeur du sruk de Sañvey ;

- le Mratāñ de Jeñ Sthalā du sruk de Vnur Phlān ;

- le Kaṃsten (chargé du service) des taureaux sacrés ${ }^{84}$, du sruk de Dakșiṇa ;

- le Loñ Vit du sruk de Vnur Phlān ;

- le Loñ Gat du sruk de Vnur Phlāí ;

- le Loñ Vāk [et] le Loñ Bhīma du sruk de Sañvey ;

- le Loñ Jaya du sruk de ...;

- le Loñ Narāy du sruk de Vnur ;

- le Loñ Sama du sruk de Vrah 'Ura ;

- le Loñ Vrahma du sruk de Lāgā Chmar.

Au total, 16 cuisiniers (à savoir les Loñ). Fabricants de feuilles, chefs militaires, gardiens de l'or et de l'argent :

- le Loñ Śrī Śarabha ;

- le Loñ Sān de Dhanipura ;

- le Loñ Den், notable (mahāpurușa) ${ }^{85}$;

- le Loñ Vit ... ;

... (lacune) ...

- ... la sainte eau ${ }^{86}$;

81. La séquence exacte nām vat semble être inconnue ailleurs dans le corpus, mais elle est comparable à nām canvat, face A, 1. 13.

82. Cf. infra commentaire, p. 59-60.

83. Cf. infra commentaire, p. 60-61.

84. Cf. K. 254, face B, 1. 2-3 : gāl ta varna nā vrah canmāt, « je servais dans la caste (chargée du service) des taureaux sacrés » (1051 śaka; IC III, p. 185 et 190). Sur l'identification de canmāt, « taureau », cf. Cœdès 1936, p. 20 n. 5.

85. Il semble que ce mot pourrait être équivalent au terme purușapradhāna qu'on vient de voir dans les lignes 25 et 27 .

86. La mention de $v$ rah dik « sainte eau » correspond peut-être à une fonction qu'il n'est plus possible de déterminer en raison de la longue lacune de la fin de la ligne 11. On peut penser au 'muh dik srón, « chauffeur de l'eau des ablutions » (par exemple K. 324, piédroit sud 1. 26; 815 śaka; NIC II-III, p. 62), mais il est difficile de proposer une restitution satisfaisante, à moins de proposer un dérivé de sroñ « le 


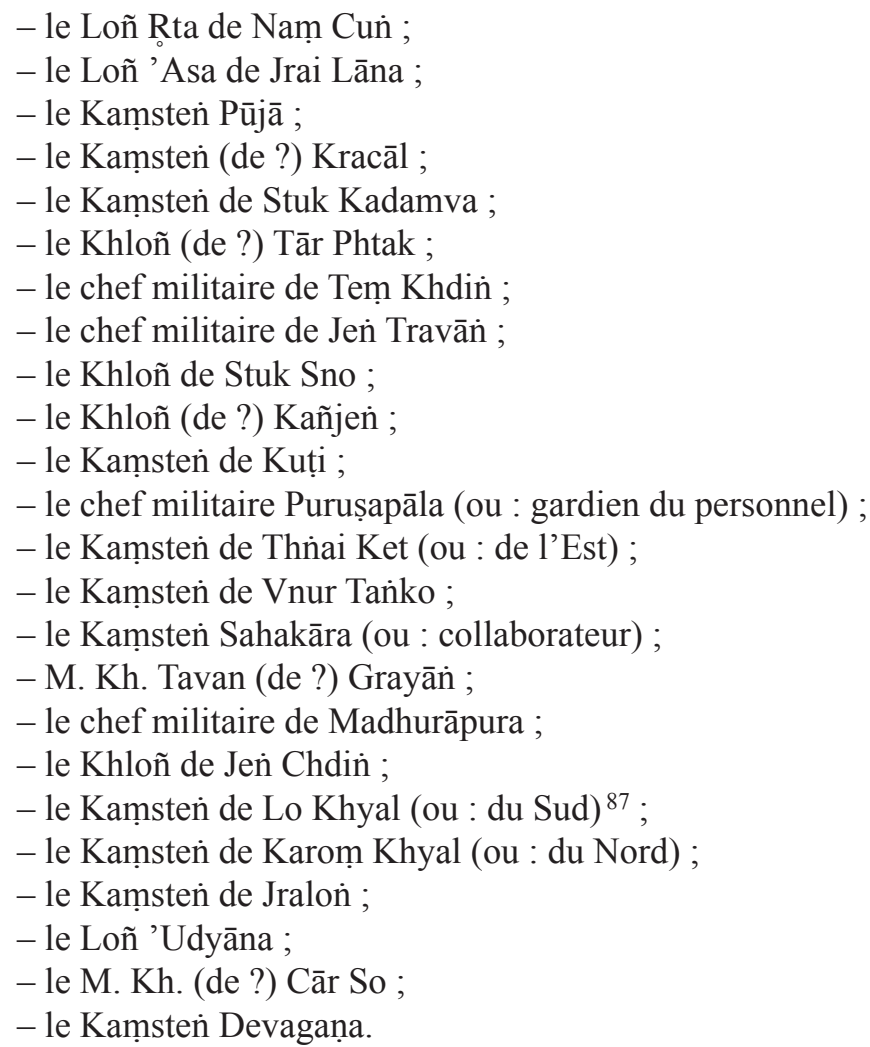

(A37-39) 1 rizière à l'est-sud-est de celle-là ${ }^{88}$, proche de celle-là, longue de 50 [unités], fut consacrée (jvan ${ }^{89}$ par le Kaṃsten் de Travān Krave, avec le chef militaire [et]

bain » permettant d'expliquer les deux premiers akșara du début de la ligne 12 (roñ). Par ailleurs, la seule autre occurrence de la séquence $v r a h$ dik relevée dans le corpus épigraphique khmer ne correspond pas, selon l'interprétation de Cœdès, à une fonction : yajña vrah dik nu bhikșā « le sacrifice au dieu, l'eau et la nourriture » (K. 258, face A 1.79 ; XI ${ }^{\mathrm{e}}$ saka; IC IV, p. 181, 198); dans ce cas vrah ne qualifierait pas dik et, pour autant qu'on le sache, il n'est pas évident que ce soit le cas dans notre inscription.

87. lo khyal - pour le khyal - désigne le sud (cf. Lewitz 1970) ; on notera que ce Kaṃsteñ, le suivant (karom khyal, « le nord ») et un troisième à la ligne 35 (thriai ket, « l'est ») sont désignés par des directions cardinales en khmer. Il s'agit ici plus vraisemblablement de toponymes que d'anthroponymes, mais on peut se demander s'il s'agit de noms de communes proprement dits - c'est par exemple le cas des sruk vāruni (face A, 1. 8, 9, 13, 28, 29) et sruk dakșina (face A, 1. 31), communes de l'ouest et du sud où les directions sont exprimées avec des termes empruntés au sanskrit - ou s'il faut voir dans ces Kamsteñ des fonctionnaires en charge des parties de l'empire khmer, ou des parties de la région dans laquelle était installée cette stèle, situées dans ces directions. À notre connaissance, ce type de dénomination n'est pas très répandu; on notera pourtant des loñ thriai ket (Loñ de l'est) et loñ thriai luc (Loñ de l'ouest) dans l'inscription K. 353 N (1. 41-42; 968 śaka; IC V, p. 137).

88. Si la première terre (dont les dimensions ont été précisées aux lignes $\mathrm{A}, 16-17)$ est bien celle du Travān La'ak, on peut supposer qu'il est question ici de celle du Travān Brāhmaṇa (face A, 1. 10).

89. On notera qu'on trouve dans ce paragraphe les seules occurrences de jvan et que c'est le verbe 'oy qui est utilisé partout ailleurs quand il est question de « donner». Ceci semble concorder avec le fait que la terre est ici directement offerte à la divinité, par opposition aux autres qui sont données à un particulier en remboursement de dettes (face A, 1. 12; face B, 1.21); on postule donc, au moins pour la période angkorienne, une différence de sens entre les deux verbes - différence dont la compréhension des finesses sémantiques impliquerait une étude systématique des occurrences - que l'on traduit, provisoirement, par l'utilisation pour jvan de « consacrer », bien adaptée dans le cas d'une offrande à une divinité. 
le Khloñ Jnval, et avec le Loñ Veda [et] le Loñ Hasa, au V. K. 'A. Śivalinga du sruk de Narendrālaya ${ }^{90}$. Qu'elle dépende de l'autorité de Loñ Śrīviṣnu, de Teñ Vija et de leur lignée à partir de [maintenant]. Défense est faite qu'elle dépende désormais de l'autorité de ces gens qui [1']ont consacrée ou de celle de la lignée de ces gens qui [1']ont consacrée ${ }^{91}$.

(A39-41) En 925 śaka, cinquième [jour] de la quinzaine sombre d'âśvayujya ${ }^{92}$, un enquêteur pour un procès [concernant] la plainte du Loñ Las, jeune chanteur ${ }^{93}$, [et] la défense du Loñ Bhīma, gardien de la chambre à coucher, [et] du Loñ Ṅe, entré au service ( ta dau $n \bar{a}$ ) [de la corporation] des saints vêtements ${ }^{94}$, [mena une enquête sur] l'origine et l'histoire de la terre ${ }^{95}$ de la commune, la rizière de la portion du jeune chanteur et les cinq petites ${ }^{96}$ rizières ${ }^{97}$ appartenant au chanteur, qui assurent ${ }^{98}$ les fournitures rituelles du saint Śivalinga, [à raison] de cinq lih de riz décortiqué chaque mois.

(A41-43) Alors, il y eut un ordre royal (vrah karunāa) enjoignant (pi pre) le M. Kh. (de ?) Bhavakșetra d'aller inspecter, de faire un plan (khpvar) ${ }^{99}$, et de [le] ramener.

90. Le Kaṃsteñ de Travān Krave et le Khloñ Jnval peuvent être identifiés au Loñ Rau et au Loñ Pat de la liste des membres du Varṇāśrama des lignes A, 7-9, mais les trois autres ne sont pas identifiables avec certitude à des personnes figurant ailleurs dans le texte.

91. L'expression 'āyatta apparaît ailleurs dans une construction avec lèn, par exemple dans l'inscription K. 235 : leñ kam pi kamvujadeśa neh 'àyatta ta javā ley, « que jamais plus ce Kambujadeśa ne dépende de l'autorité de Javā » (face C, 1. 72 ; 974 śaka ; Coedès \& Dupont 1943-1946, p. 87 et Sak-Humphry 2005 , p. 102). Le sens proposé, « dépendre de l'autorité de », ne semble pas y poser de problème et convient aussi parfaitement à notre contexte. En revanche, on notera que Cœdès l'interprète transitivement dans l'inscription K. 195 : 'nak ta 'addhyāpaka lè 'àyātta 'āśrama noh, « que celui qui est professeur exerce son autorité sur cet āçrama» (1. 18-19; $x^{\mathrm{e}}$ śaka; IC VI, p. 248, 250). Cette dernière occurrence devra sans doute être reconsidérée.

92. Soit le 19 septembre 1003 de notre ère (Billard \& Eade 2006, p. 414).

93. Le « corps des pages », kanmyan் pamre, est évoqué à plusieurs reprises dans les inscriptions, sans que ses attributions soient précisées (par ex. K. 158, face A, 1. 4 ; 925 śaka; IC II, p. 99). Il est possible de supposer que kanmyan் cammryan, « jeune chanteur ", corresponde à l'une des fonctions que ce corps assurait, en particulier à la cour du roi.

94. Rien n'indique explicitement que ces différentes fonctions - jeune chanteur, gardien de la chambre à coucher et [membre de la corporation] des saints vêtements - soient spécifiquement attachées à la maison du roi. Cependant, cette hypothèse est très vraisemblable dans le cas du gardien de la chambre à coucher. Dans ce cas, il faudrait peut-être traduire vrah vasana, par « vêtements royaux ». L'expression vrah vasana dans le sens de " saint vêtement », "vêtement du dieu », apparaît à plusieurs reprises dans les listes de bien des divinités dont nous disposons (par ex. K. 34, face B 1. 18 ; xi śaka; IC III, p. 154, 156); en revanche les rares inscriptions où elle apparaît dans un nom de fonction ne permettent pas de la préciser. On notera en particulier la mention de Vāp qui sont dits dmuk vraḥ vasana so, « dépositaires des Saints vêtements blancs » (K. 262, piédroit sud, 1.14 ; 904 śaka ; IC IV, p. 112); la traduction que nous avons choisie est fondée sur l'interprétation par Cœdès de la ligne 4 de la même inscription (IC IV, p. 115, n. 6).

95. Le mot śăka égale śākha (Pou 2004, s.v., p. 526 et suiv.). Cf. śloka neh tem śákha bhümi..., « ce poème (qui relate) l'origine et les ramifications des terres... ", dans l'inscription K. 158 (face A, 1. 3 ; 925 śaka ; IC II, p. 99, 105) et tantyaì (...) tem śākha bhümi, « demandant (...) l'histoire de la terre » dans l'inscription K. 262 (piédroit sud, 1. 1-2; 904 saka ; IC IV, p. 111, 115).

96. À notre connaissance, il s'agit de la première attestation de 'amvok(a) dans le corpus. Suivant une suggestion de Michael Vickery, nous considérons 'amvok comme le correspondant du moderne ambok, /Ramposk/, « small (of rice fields or ponds only) » (Headley et al. 1997, s.v., p. 1594).

97. Remarquer la différence avec la face B, 1. 2 : sre camhura pvāna 'amvoka « les quatre petites rizières irriguées $»$.

98. Pour cette interprétation de la construction de ti cām camnnām, cf. K. 33, 1. 23 (939 śaka; IC III, p. 150 \& 151) et K. 420, 1. 30-31 ( $\mathrm{xI}^{\mathrm{e}}$ saka; IC IV, p. 162, 165).

99. Cf. infra commentaire, p. 61. 
Puis (pi), le Kaṃsteñ (de ?) Śivapāda, président de l'assemblée de troisième rang, enquêteur de l'assemblée royale [pour le procès (vyavahāra, cf. 1. 40)], le plaignant le Loñ Las, les contre-plaignants ${ }^{100}$ le Loñ Bhīma [et] le Loñ $\dot{N e}$, reçurent l'ordre royal d'aller et de s'assurer que les anciens de la commune et des propriétaires terriens inspectent et fassent le plan conformément à l'ordre royal.

(A43-44) L'assemblée royale inspecta et fit ledit plan [conformément à] l'ordre royal. Ceci achevé, de concert avec le plaignant et le contre-plaignant, ce sont eux qui ramenèrent le cuir ${ }^{101}$ [résultant] de l'inspection à l'assemblée royale. Le plaignant Loñ Las a assisté pendant sept mois ; les contre-plaignants, le Loñ Bhīma [et] le Loñ Ṅe, en fuite, n'ont pas assisté.

(A45-47) Le Kaṃsten (de ?) Śivapāda, président de l'assemblée de troisième rang, de concert avec le M. Kh. Śrīsaānapaṇdita, inspecteur des qualités et des défauts, et avec le M. Kh. de Yanap, récitateur du saint Dharmaśāstra, transmirent alors l'édit royal au Loñ Las qui avait assisté pendant sept mois - les contre-plaignants, le Loñ Bhīma [et] le Loñ $\dot{\mathrm{Ne}}$, ayant été en fuite pendant les sept mois -, ordonnant que le Loñ Las soit vainqueur conformément à l'injonction royale.

(A47-48) Étaient présents, quand le Kaṃsten (de ?) Śivapāda, président de l'assemblée de troisième rang, transmit [l'ordre] : le M. Kh. Śríśānapaṇ̣ita, le M. Kh. de Yanap, récitateur du saint Dharmaśāstra, le M. Kh. (de ?) Bhavakșetra, le Steñ Bhavanāditya [et] tous les autres [membres] de l'assemblée royale.

(A48-B2) En 946 śaka, sixième [jour] de la quinzaine claire de kārttika, un lundi ${ }^{102}$, j'ai ${ }^{103}$ conduit le Loñ Nārāyaṇa, du sruk de Jen̉ Chdiñ, province de Jeñ Tarāñ, en présence de l'assemblée royale ${ }^{104}$ : il m'avait emprunté avec intérêt un capital (tem d'un $p \bar{a} d a$ d'or, deux fois (pour intérêt) ; un capital d'un jyan de cuivre, deux fois (pour intérêt) ; une boîte en argent, deux fois (pour intérêt) ; une marmite à chaux en argent, deux fois (pour intérêt).

100. Les mots 'arthi/pratyarthi trouvent leur origine en sanskrit (arthin/pratyarthin, «plaignant/ contre-plaignant »), dénotant ceux qui portent plainte et la défense ('artha/prathyartha; cf. A, 1. 40). Voir K. 1052 = Ka 442 = K. 1183 (face A, 1. 17-18 ; Vong Sotheara 2005, p. 14 ; lecture vérifiée sur l'estampage EFEO n. 1679) : 928 śaka navami ket jyeștha (ś) ukravāra nu cāre vyavahāra neh o toya gati vyavah[āra] \{4\} ['u]ttama ta ti 'arthi 'oy' pi pratyarthi pracāy• rohha nehha $\circ$, « En 928 śaka, neuvième [jour] de la quinzaine claire de jyeșțha, un vendredi, l'enquêteur pour ce procès révéla sur la procédure ... supérieur a été donné par le plaignant au contreplaignant, en enjoignant de l'utiliser ainsi (lire pre cāy ?) ».

101. Cf. infra commentaire, p. 61.

102. Soit le dimanche (et non lundi !) 11 octobre 1024 de notre ère (Billard \& Eade 2006, p. 416).

103. La suite du texte permet d'identifier le narrateur au M. Kh. de Danlān, dans lequel on reconnaîtra également le V. K. 'A. Narendravarman de la première partie du texte (cf. p. 35).

104. Cf. K. 262 (piédroit sud, 1. 6-7 ; 904 śaka ; IC IV, p. 111, 115) : ... ti V. K. 'A. nām dau samakșa $n u$... « amené par V. K. A. (Divākara) en présence de... ». Nous présumons que la construction nām dau samakṣa nu ... est équivalente à notre nām ... mok samakșa 'āy. 
(B2-4) Le Loñ Nārāyaṇa [m']a donné quatre petites rizières irriguées ${ }^{105}$, avec une résidence [de type] Catuhśāla ${ }^{106}$, en remplacement desdits biens. Ces rizières et cette résidence ont été données par moi à mon enfant qui s'appelle Loñ Śrīviṣnu, à mon épouse qui s'appelle Ten Rudrānī, à mon beau-frère ${ }^{107}$ qui s'appelle Vāp Sān et à l'ensemble de cette famille. Tous ceux-là furent interrogés par l'assemblée royale pour confirmation.

(B4-8) En 946 śaka, sixième [jour] de la quinzaine claire de kārttika, (ce même) lundi ${ }^{108}$, le V. K. 'A. Phalapriya, président de l'assemblée de troisième rang, le Kamısteñ de Yanap, récitateur du saint Dharmaśāstra, le Kaṃsteñ des orfèvres, assesseur, le Kaṃsten (de ?) 'Amvil, le chef militaire (de ?) Rājaprasāda, inspecteur de l'assemblée royale, ensemble transmirent l'édit royal au Loñ Nārāyaṇa : ces quatre rizières avec cette Catuhśāla sont données au M. Kh. de Danlān pour prix de ces deux pāda d'or, de deux boîtes en argent, de deux marmites à chaux en argent et de deux jyan de cuivre, en droit exclusif ${ }^{109}$ au M. Kh. de Danlān. Défense est faite que le Loñ Nārāyaṇa accomplisse du service (royal ou divin) avec ça ${ }^{110}$.

(B8-10) Pour ce qui concerne (nā) d'une part (dai), le M. Kh. de Danlāin et d'autre part (dai $)^{111}$, le droit exclusif sur cette terre de Vāp Sān et de ladite famille : cette [terre]

105. sre caṃhura pvāna 'amvvoka : nous considérons ici caṃhura comme une variante de canhvar (p.a. canhor), dérivé de hor/hvar " couler », et désignant une « rigole, [un] ru » (Pou 2004, s.v., p. 157). Ce terme est utilisé dans plusieurs hydronymes (Long Seam 1993, p. 136). Suivant ici une interprétation de Philip N. Jenner, nous considérerons que caṃhura qualifie quatre petites rizières " irriguées »; ces terres correspondent vraisemblablement à celles qui sont évoquées en $\mathrm{A}, 1.41$, ou peut-être à une partie d'entre elles, puisqu'elles étaient alors au nombre de cinq.

106. Pour ce qui concerne catuhśála, nous ne disposons que d'une occurrence de bhümi catuśśâla dans le corpus, où ce terme est interprété par George Cœedès comme un toponyme (K. 260, piédroit nord, 1. 8 ; $\mathrm{XI}^{\mathrm{e}}$ śaka; IC IV, p. 174). Le fait qu'ici catuhśsāla soit associé à quatre rizières pourrait inciter à penser qu'il s'agit de quatre maisons distinctes. Cependant, l'expression sre noh ta pvāna nu catuhśāla (B, 1. 7,15$)$ est manifestement équivalente à sre ta pvān nu padah valaya mvāy $(\mathrm{B}, 1.18)$; dans ce dernier cas, une seule ( $m v \bar{a} y)$ résidence cloturée (padaḥ valaya) est évoquée, ce qui permet de penser qu'il ne s'agit en fait que d'une seule maison à quatre salles.

107. À propos de khlai « beau-frère », cf. Griffiths 2005, p. 22, n. 36.

108. Il s'agit de la même date que la précédente (A, 1. 48), soit le dimanche 11 octobre 1024 de notre ère (Billard \& Eade 2006, p. 416).

109. À propos de l'interprétation de siddhi comme « droit exclusif», et sur l'importance que celui-ci soit reconnu « sans contestation » pour valider des transactions foncières, voir Sahai 1970, p. 110111 : «Un individu ne pouvait être considéré comme propriétaire légitime avant que le tribunal ne lui eût attribué le droit exclusif (siddhi) sur la terre qu'il avait achetée ou reçue en don, et que l'ancien propriétaire ne lui eût abandonné formellement son droit exclusif. En cas d'attribution ou de vente illégitime d'une terre, le propriétaire lésé avait le droit de faire objection (apavâda) et d'intenter un procès. » Les déclarations enregistrées au début (face $\mathrm{A}, 1.9-11$ ) et à la fin de cette inscription (face $\mathrm{B}$, 1. 21-30) insistent en effet sur l'absence de contestation quant à la propriété des débiteurs, avant qu'ils n'en transmettent le droit à Narendravarman/M. Kh. de Danlāṅ.

110. L'expression vvam 'âc=ti loñ. narāyana sveñ $\cdot k \bar{a} r y y a$ nu gi est difficile. On trouve un parallèle exact dans K. 1187, face B, $1.8: \ldots$ vvam 'a $\bar{c}=t i$ s(v)en $k \bar{a}[r]$ yya $n u$, suivi d'une liste de biens (942 śaka ; estampage EFEO n. 1686 ; Chaem Kaewklai 1999, p. 87). Selon Saveros Pou, sven signifie " parcourir un long chemin, rechercher» (2004, p. 521). Sur la base d'autres passages tels que K. 256, piédroit $\mathrm{V}, 1.12-13$ : vāp vis lak bhümi neh phon pi yok dravya ta rohh neh ti thve rājakāryya nu gi (901 śaka; Cœdès \& Dupont 1937, p. 405), K. 262, piédroit sud, 1.28 : ... thve devakāryya nu gi (904 śaka; IC IV, p. 112) et K. 702, face B, 1.9 : ... pi santāna thve rājakāryya nu gi (947 śaka; IC V, p. 225), qui semblent proches, nous supposons que sven dans notre contexte et dans celui de K. 1187 équivaut à peu près à thve « faire ».

111. La construction ... dai ... dai était jusqu'ici inconnue dans le corpus, mais nous l'avons trouvée aussi dans une autre inscription contemporaine de la nôtre, K. 1186, sur la face A, 1. 5-6 (estampage 
fut achetée par le M. Kh. pour [1a] donner en droit exclusif, conformément au témoignage (praśañsā $)^{112}$ du M. Kh. de Danlān. Alors, ce document de l'enquêteur fut emmené au V. K. 'A. de Kuṭi Ruñ, président de l'assemblée de premier rang. Le Loñ Nārāyaṇa a confirmé sous serment.

(B10-12) Alors, conformément à ce document, le V. K. 'A. de premier rang ordonna (d'accorder) le droit exclusif au bénéfice du M. Kh. de Danlān. Alors, [la terre] fut donnée par le M. Kh. de Danlān à ces gens (Loñ Śrīviṣṇu, Teñ Rudrāṇī, etc. B, 1. 3-4), en leur droit exclusif.

(B12-14) Alors, ce document fut emmené par moi (le M. Kh. de Danlāñ) et par le Loñ Nārāyaṇa au V. K. 'A. (de ?) Ven Jeń, président de l'assemblée de quatrième rang. Le V. K. 'A. interrogea le Loñ Nārāyaṇa qui confirma sous serment tous les mots (pada) ${ }^{113}$ qui composent (man roḥ) ce document. Le V. K. 'A. (de ?) Ven Jen, président de l'assemblée de quatrième rang, était accompagné par le Kaṃsteñ (de ?) Kaden, récitateur du saint Dharmaśāstra, le Kaṃsteñ de 'Aśvapattana [et] le Kaṃsteñ du Vraḥ 'Āśrama.

(B14-17) Alors, le Loñ Nārāyaṇa confirma sous serment qu'il y avait deux pāda d'or, 2 boîtes en argent, 2 marmites à chaux en argent, 2 jyañ de cuivre, empruntés avec intérêt ; puis ( $p i)$ [qu']il avait donné ces quatre rizières avec cette unique Catuhşāala en droit exclusif au M. Kh. de Danlān. Alors, ces rizières et cette Catuhśâla furent données par le M. Kh. de Danlān à son fils appelé Loñ Śrīvișṇu ${ }^{114}$ et à la mère (du Loñ Śrīviṣnu et donc la Teñ Rudrāṇ̄i ?) [et] ${ }^{115}$ à l'ensemble de cette famille en leur droit exclusif.

(B17-21) En 948 śaka, huitième [jour] de la quinzaine claire de vaiśākha ${ }^{116}$, l'assemblée royale interrogea le Loñ Nārāyaṇa. Déclaration du Loñ Nārāyaṇa qui était à l'origine jeune chanteur, puis entra dans la corporation des fabricants de feuilles au côté du (mvāy mūla $n u)^{117} \mathrm{M}$. Kh. de Danlān. Voici quatre rizières avec une résidence clôturée, une portion (héritée) de ma propriété. Alors, le roi (vrah) ayant ordonné de recueillir de l'or de toute

EFEO n. 1684 ; 935 śaka ; Chaem Kaewklai 1999, p. 82) : dharmma gurujana dai nu jananiya dai nu mratāña śri nrpendravāllabha « fondation pieuse des parents de l'un, de la mère de l'autre et du Mratāñ Śrī Nrpendravallabha ». Notre interprétation adversative de la fonction de la construction répétée semble la seule possible dans le cas présent.

112. Il semble que ce terme, qui devrait normalement (vue son origine sanskrite) être un synonyme de praśasti, soit un hapax en vieux khmer. On présume qu'ici, il renvoie au passage précédent formulé à la première personne (face B, 1. 2-4), dans lequel le M. Kh. de Danlān accorde le droit exclusif sur ces biens à sa famille.

113. Ce mot d'origine sanskrite ne semble pas avoir été relevé en vieux khmer dans ce sens jusqu'ici.

114. Malgré l'incohérence d'orthographe indéniable (cf. n. 39) et les incertitudes de lecture, on considérera que le nom de ce personnage est bien śrīvișnu (c'est-à-dire Śrīviṣṇu) et non śrīvișna.

115. Cf. face B, 1.3-4 : $t i$ 'aña 'oy· sre noḥ (nu) pada(h) noḥha ta kvan· 'añ. ta jmah loña śrivișnu nu

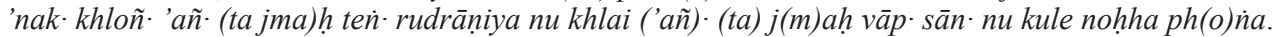
Le parallélisme avec ce passage invite à supposer l'omission d'un $n u$ entre 'me et kule par le lapicide.

116. Soit le 27 avril 1026 de notre ère (Billard \& Eade 2006, p. 416).

117. Concernant la séquence $m v \bar{a} y$ mūla $n u$, on notera qu'elle apparaît dans l'inscription K. 450, 1. 22-23 : mañgalārthavargga ta mvāy mūla nu vrah kaṃmraten் 'añ śrī rājendrapandita, « le groupe des Mañgalārtha ayant ensemble pour chef (müla) le V. K. A. Śrī Rājendrapaṇịita » ( $\mathrm{x}^{\mathrm{e}}$ śaka ; IC III, p. 111, 113) et dans l'inscription K. 598, face B 1. 52-53: mratāñ [khloñ] pañgam thpvañ nivedana kule mratāã śrī kavīndravijaya mvāy mūl nu kule mratāñ khloñ nā bhāgavata pammre, "Celui-ci déclara respectueusement que leurs deux familles servaient ensemble comme bhägavata» (928 śaka; NIC IIIII, p. 233 \& 237). On peut la comparer à la construction ... sam mūla nu ... dans l'inscription K. 165 N, 1. 17 , « se sont associés à » $(874$ śaka; IC VI, p. 135, 138). Nous en concluons que l'élément mūla ne porte vraisemblablement pas le sens de «chef » dans de tels contextes et suivons alors l'interprétation de Pou pour K. 598. 
l'équipe (sakarmma sap), tout le monde (prajā phoi), nous avons emprunté à intérêt un $p \bar{a} d a$ d'or, une boîte en argent, une marmite à chaux en argent, 1 jyañ de cuivre. Le service royal fut donné avec cela par le M. Kh. de Danlān. L'intérêt sur les biens étant comme susdit. Dépourvu [de biens] à donner, j'ai pris ces rizières avec cette résidence clôturée. Je [les] ai données [pour] prix des biens [empruntés au] Mratāñ Khloñ de Danlān, il y a (mān jā ?) quinze années ${ }^{118}$.

(B21-22) Déclaration du chef militaire de Kamven : cette terre a été vendue par le Loñ Nārāyaṇa au M. Kh. de Danlān ; terre du Loñ Nārāyaṇa, héritée de sa lignée, il n’y eut jamais ${ }^{119}$ de discussion ${ }^{120}$.

(B22-23) Déclaration du Mratāñ Khloñ principal, neveu du Kaṃsten̉ Bhavanāditya : cette terre a été vendue par le Loñ Nārāyaṇa au M. Kh. de Danlān ; terre du Loñ Nārāyaṇa, héritée de la lignée du Loñ Nārāyaṇa, il n'y eut jamais de discussion.

(B23-25) Déclaration du Loñ 'Yak de 'Ugrāvāsa, ancien de la commune : cette terre a été vendue par le Loñ Nārāyaṇa au M. Kh. de Danlān ; terre du Loñ Nārāyaṇa, héritée de sa lignée, il n'y eut jamais de discussion ni de contestation.

(B25-26) Déclaration du chef militaire, [chef de] dix communes, Śivagandha : cette terre a été vendue par le Loñ Nārāyaṇa au M. Kh. de Danlān ; terre du Loñ Nārāyaṇa, héritée de sa lignée, il n'y eut jamais de discussion.

(B26-27) Déclaration du Loñ Gandharva, ancien de la commune : cette terre a été vendue par le Loñ Nārāyaṇa au M. Kh. de Danlān ; terre du Loñ Nārāyaṇa, il n'y eut jamais de discussion.

(B27) Déclaration du M. Kh. (de ?) Camvyar ${ }^{121}$ : cette terre est la terre du Loñ Nārāyaṇa. Elle est depuis longtemps ${ }^{122}$ travaillée (thve) par le Loñ Nārāyaṇa. C'est connu de moi également.

(B27-28) Déclaration du Loñ Vrah de Vnur 'Aṃvi : cette terre a été vendue par le Loñ Nārāyaṇa au M. Kh. de Danlān ; terre du Loñ Nārāyaṇa, héritée de sa lignée, il n’y eut jamais de discussion.

(B29-30) Déclaration du Loñ principal, appelé Loñ 'Āditya : cette terre que le Loñ Nārāyaṇa a vendue au M. Kh. de Danlān, la terre du Loñ Nārāyaṇa, a été donnée par mes ancêtres au ... de Loñ Nārāyaṇa. Le droit exclusif est [au] Loñ Nārāyaṇa, depuis longtemps. Défense pour nous de contester.

118. L'expression mān jāa ne semble exister nulle part ailleurs dans le corpus, mais le sens du texte paraît imposer l'interprétation que nous en donnons.

119. L'expression ... vvam tel ..., « encore jamais », apparaît deux fois à la ligne 4 de K. 175, face est (IX śaka ; IC VI, p. 175, 178) ; voir aussi Jacob 1991, p. 207, 211 (réimpr. , p. 193, 197).

120. En regard du caractère évidemment formulaire des dépositions reproduites dans cette partie de l'inscription (1. 22-28), il est étonnant de relever plusieurs variations dans les formules : deux fois neh pour noh ; une fois la spécification de Loñ Nārayana après 'amvvi ta santāna; une fois vāda 'apavāda pour $v \bar{a} d a$ et une omission de 'amvi ta santāna.

121. Le mot camvyar n'apparaît dans le corpus que comme anthroponyme dans la forme préangkorienne camver (K. 480, 1. 10 ; vi śaka; IC II, p. 191).

122. Le mot 'ven était inconnu jusqu'ici, seule la forme veri, « long», sans occlusive glottale initiale, ayant été attestée ; il apparait aussi à la 1.30 de la face B. Il s'agit manifestement de la base du dérivé 'amveñ « longueur » (Pou 2004, s.v., p. 22). Sur pradvan, voir note 60 sous A, 1. 9-11. Pour la combinaison pradvan 'ven, nous postulons le sens « depuis longtemps ». 


\section{Commentaires}

\section{Face A, l. 2 : kamptvan}

Le mot kamtvan apparaît fréquemment dans la titulature de Sūryavarman $\mathrm{I}^{\mathrm{er}}$ et est également utilisé, bien que très rarement et toujours dans des références posthumes, pour Jayavarman II (K. 956, 1. 19 ; $\mathrm{X}^{\mathrm{e}}$ śaka ? ${ }^{123}$; IC VII, p. 130) et Yaśovarman I ${ }^{\mathrm{er}}(\mathrm{K} .158$, face c, 1. 8-9 ; 925 śaka ; IC II, p. 104), puis, juste après la fin du règne de Sūryavarman I ${ }^{\mathrm{er}}$, deux fois pour désigner Udayādityavarman II (K. 235, face D, 1. 70 ; 974 śaka ; Codès \& Dupont 1943-46, p. 91 et K. 1158, face A, 1. 36 ; 988 śaka ; Chirapat Prapandvidya 1990, p. 12). À moins que l'inscription K. 956 s'avère après tout antérieure, nous croyons vraisemblable que cet élément de titulature soit une création du règne de Sūryavarman I ${ }^{\mathrm{er}}$. Quoi qu'il en soit, il s'agit très probablement d'un dérivé à préfixe kam- de tvan " grandmère » (cf. par ex. ven் « long » / kam-ven் « enceinte », śrī « beauté » / kam-śrī « beau »), comme l'avait déjà proposé Étienne Aymonier en 1904 (p. 496), idée acceptée en 1954 par George Coedès (IC VI, p. 9, n. 3), après qu'il l'eut longtemps considéré comme un dérivé du malais tuan, « maître ». Les parties sanskrites du corpus épigraphique de l'époque de Sūryavarman I ${ }^{\text {er }}$ suggèrent assez explicitement que la légitimation de son pouvoir se trouvait en ligne maternelle (cf. Vickery 1985, p. 240, n. 64 ; Chakravarti 1982, p. 70). Les passages afférents sont K. 136, face B, st. I ( $\mathrm{x}^{\mathrm{e}}$ śaka; ISC, p. 130); K. $253 \mathrm{~N}$, st. III (927 śaka; Cœdès 1911, p. 223) ; K. 702, st. VIII (947 śaka; IC V, p. 224). Le dictionnaire de Saveros Pou (2004, s.v., p. 84) donne « Parents descendant de la même grand-mère, en ligne maternelle ». Il est surprenant que le glossaire de Sak-Humphry donne d'abord (2005, p. 199, avec les notes 14 et 15) une interprétation de la forme angkorienne du mot comme «maître », puis (p. 213) explique de la façon susindiquée sa forme préangkorienne kamton. Notre traduction « par succession matrilinéaire » manque peut-être de littéralité, mais permet de distinguer cette expression de toy mätrpakșa (par ex. face A, 1. 10), qui pourrait s'avérer synonyme, mais que, faute de certitude, nous traduisons provisoirement « en ligne maternelle».

\section{Face A, l. 2 : varṇnāśrama}

Sur le terme varn(n)āśrama, on consultera l'article de I. W. Mabbet (1977, p. 437438). Il nous semble qu'il reste « difficult to do more than speculate about the Cambodian usage of the expression » et nous partageons l'impression de Mabbet que varnāśrama en contexte khmer « is a general term referring to families or communities of dignitaries ». Il nous est difficile d'approuver la suggestion de S. Pou (2002, p. 329 ; voir aussi p. 334) selon laquelle «le mot semble être une création propre aux locuteurs khmers, à savoir un composé fait de termes sanskrits agencés selon la syntaxe khmère » et qu'il soit possible par conséquent de l'interpréter comme «varna des àśrama». Nous ne connaissons pas d'autres cas où le sandhi sanskrit serait appliqué dans des telles constructions possessives khmères. $\mathrm{Si}$ - comme tous les khmérisants semblent maintenant le penser - un varna est une sorte de corporation et si (au départ au moins) un āśrama correspond à un site, l'interprétation tatpurușa du composé emprunté au sanskrit reste la plus probable ; selon la tendance de la langue khmère à admettre des emplois partitifs (Pou 2002, p. 325) de noms collectifs, on peut donc proposer une explication telle que « (membres de) l'āśrama

123. La datation du IX $X^{\mathrm{e}}$ śaka proposée par Cœedès pour K. 956 est incertaine ; l'écriture cursive utilisée nous semble en effet très proche de celle de l'inscription K. 1186, attribuable au règne de Sūryavarman I ${ }^{\text {er }}$ (935 saka; estampages EFEO n. 1684 et n. 1685). 
des corporations », traduction dont nous soulignons le caractère strictement diagnostique. Les membres de ce corps, ou en tout cas ceux qui sont débiteurs de Narendravarman, sont identifiés sur la face A, 1. 7-9, 13-15, 37-38. On notera qu'ils proviennent d'au moins deux localités et que plusieurs professions sont représentées.

\section{Face A, l. 5 : sañ gol praśasta}

La séquence san gol praśasta, qui apparaît fréquemment - avec parfois des variantes dans le corpus, a été interprétée de façons diverses par George Cœdès dans les différents tomes de ses Inscriptions du Cambodge. Cf. K. 570, 1. 33 : san gol praśasta, "planter les bornes sacrées » (891 śaka; IC I, p. 145); K. 566, face B 1. 21 : sāñ gol praśas[ta], «planter les bornes » ( $\mathrm{x}^{\mathrm{e}}$ śaka; IC V, p. 184-185); K. 913, 1. 6 : san gol praśasta $\left(\mathrm{x}^{\mathrm{e}}\right.$ śaka; IC V, p. 270-271); K. 343, piédroit sud 1. 17-18: sā [n gol] praśasta, « planter les bornes fixées par l'édit» (896 śaka; IC VI, p. 157); K. 181, face A 1. 7 et 14, B 1. 1 et 7-8 : tok/ sam gol praśasta, " arracher / planter les bornes ... fixées par ordonnance » (884 śaka; IC VI, p. 140-141) ; K. 229, 1. 8 : gol praśasta, « les bornes fixées par l'édit (praśasta) » ( $\mathrm{x}^{\mathrm{e}}$ saka; IC VI, p. 273, 274); K. 957, face A, 1.6 : sain gol praśasta, « planter les bornes prescrites (praśasta)» (863 śaka; IC VII, p. 138-139). Puis, Saveros Pou a traduit par " planter des bornes d'inscription » l'occurrence de san gol praśasta dans K. 1116, face A, 1. 11 (913 śaka; NIC II-III, p. 145 \& 147). Pour ce qui concerne ce problème de traduction, on notera surtout à la face $\mathrm{B}, 1.1$ de cette dernière inscription : pre mok sañ் praśasta $n e h$, « enjoignant d'aller ériger cette inscription ». S. Pou précise : "L'expression san praśasta neh signifie litt. "planter cette inscription". Évidemment il s'agit de réparer les dégâts, en l'occurrence replanter les bornes arrachées, mais tout porte à croire que san renferme aussi l'idée de la rédaction du texte. Donc, Vāp Nārāyana était probablement l'auteur érudit de notre inscription » (NIC II-III, p. 148, n. 7). Nous choisissons donc d'interpréter la séquence problématique san gol praśasta comme dénotant deux actes. Quant à l'emploi de praśasta pour « inscription » où, du point de vue du sanskrit, on attendrait plutôt praśasti, nous renvoyons à l'article de S. Pou (1989, p. 574 : « Skt. verbal adjectives $>$ Khm. verbs or nouns »), ainsi qu'à Bhattacharya 1991, p. 63 ; Coedès a partout essayé de rendre praśasta comme s'il s'agissait d'un adjectif verbal (participe).

\section{Face A, l. 13 : guna vyar}

Grégory Kourilsky est revenu récemment sur l'interprétation « intérêt d'une dette » proposée par George Codès pour le terme guna (IC IV, p. 196, n. 1). S'étonnant du passage du sens de « qualité » ou de " mérite » à celui de « dette », il propose d'interpréter cette évolution en reliant guna à la fonction de gunadoṣadarśin, « inspecteur des qualités et des défauts ». Il remarque en effet que cette fonction et l'utilisation de guna dans le sens d' « intérêt » n'apparaissent que dans des inscriptions du $\mathrm{IX}^{\mathrm{e}}$ au XI $\mathrm{XI}^{\mathrm{e}}$ siècle de notre ère, et que ces fonctionnaires « judiciaires » sont impliqués à plusieurs reprises dans des « règlements de litiges fonciers avec l'implication de dettes et de règlements ». $\mathrm{Si}$, comme il le suppose, le rôle de ces fonctionnaires se limitait essentiellement à cela, il serait alors possible de supposer un passage par abrègement de la fonction à l'objet, guna, et d'expliquer le nouveau sens que prend ce terme (Kourilsky 2008, p. 31-32). Il est vrai que l'expression lvoh guna dravya, « rembourser/payer l'intérêt d'un bien », qui apparaît dans K. 257, piédroit nord, 1. 6-7 (916 śaka ; IC IV, p. 144 et 149, n. 1) laisse supposer que guna a bien pris le sens d' « intérêt ». Pourtant, il nous semble nécessaire de comprendre l'expression guna vyar comme un équivalent khmer du composé sanskrit dviguṇa « deux fois », la notion d'intérêt n'étant alors qu'implicite, au moins dans 
un premier temps. Cette nouvelle occurrence vient éclairer le mode de « calcul» de cet intérêt. En effet, le total des biens est égal aux biens empruntés à l'exception du nombre de crachoirs : deux avaient été empruntés alors qu'il en apparaît trois dans le total. Ceci confirme que l'intérêt n'était porté que sur le premier des biens énumérés. L'expression padigah I jyan 7 guna vyar, " 1 crachoir de 7 jyan், deux fois (pour intérêt) », implique donc qu'un autre crachoir de 7 jyan, et non deux, devait être donné comme intérêt sur l'ensemble des biens. Il est alors possible que ce soit ce fonctionnement des intérêts guna $\mathrm{x}=\mathrm{x}$ fois [en intérêt] - qui ait entraîné l'évolution du sens de ce terme. Enfin, nous manquons encore d'éléments pour expliquer le rôle exact des différents membres de l'assemblée royale, mais on notera que, si le seul inspecteur des qualités et des défauts qui apparaît dans K. 1238 joue bien un rôle dans le litige foncier de la deuxième partie, il n'est en revanche aucunement impliqué dans la question du recouvrement de la dette de la première partie et n'apparaît pas aux côtés des autres membres de l'assemblée (face A, 1. 17-24). De plus, on notera que le composé gunadoșa et la fonction de gunadoșadarśin qui lui correspond apparaissent régulièrement en Inde dans des contextes variés. Enfin, si guna était vraiment lié, au Cambodge, à des questions d'emprunts à intérêts, on serait en droit de se demander à quoi correspond alors le terme doșa.

\section{Face A, l. 14 : thnap thpir vlah}

À propos de thnap « large étoffe, couverture, étole » et de thpir « cousu », cf. Pou 2004, s.v., p. 239, 240 ; Green 2000, p. 309 ; et $I C$ III, p. 8, n. 7 ; p. 20, n. 2. Plusieurs traductions ont été proposées pour le terme vlah : « complet de vêtement (hyp.) ; mot classificateur de vêtement » (Long Seam s.d., s.v., p. 554); « Dédoubler, assembler deux choses. Double, jumeaux » (Pou 2004, s.v., p. 468) ; « unidentified unit of measure for cloth, subdivision of the yau » (Jenner 1981, s.v., p. 298). Cœdès notait : «vlah est un numéral de vêtements, qui à la 1.7 [de l'inscription K. $561 ; 603$ śaka] correspond à dvayam du sanskrit (st. V) et semble être ainsi synonyme de yugala. N'était la qualité sonore de l'initiale et la brièveté de la voyelle, on serait tenté de le rapprocher du mod. phlàs "changer (de vêtement)", dont le dérivé, littéralement "rechange", est justement employé pour les vêtements : saṃliek pír panlàs "deux vêtements" » (IC II, p. 42, n. 9). Pourtant, le rapprochement avec le terme yugala - qui qualifie des vêtements « doubles »semble impossible quand on trouve l'expression canlek yugala yau II vlah I dans l'inscription K. 79 (1. 7 ; 565 śaka ; IC II, p. 70). Ainsi, si dvayam correspond comme nous le pensons à yugala dans l'inscription K. 561, il faut renoncer à l'équivalence dvayam/ yugala/vlah que Cœdès proposait, ainsi qu'à la traduction « une paire d'étoffes cousues ». On doit donc considérer que vlah est une unité de mesure d'étoffe, subdivision du yau, dont la dimension reste à préciser. On notera que cette interprétation est retenue par Michael Vickery qui propose de considérer yau et vlah comme des emprunts à des termes austronésiens introduits au temps du Funan, ou antérieurement, par le biais de relations commerciales. Selon son analyse, en particulier par la comparaison de ces termes avec les $y u$ et blah des inscriptions javanaises, il faudrait considérer que le vlah correspond à la moitié d'un yau (1992, p. 187-188 ; 1998 : 293 ; Green 2000, p. 293, n. 20).

\section{Face A, l. 16-17 et A, l. 37-39 : les mesures de terres}

L'épigraphie khmère fournit trois autres occurrences où des formulations équivalentes à run pantoy thíāy $\mathrm{x}$ ven ta din thriāy $\mathrm{y}$, « large, d'est en ouest, de $\mathrm{x}$ [unités] et longue de $\mathrm{y}$ [unités] du nord au sud », sont utilisées pour préciser des dimensions de rizières, toutes attribuables au règne de Sūryavarman I ${ }^{\mathrm{er}}$ : K. 205, 1.4 (958 śaka; IC III, p. 4 -à propos 
de run், voir IC III, p. 8 n. 2), K. 291, piédroit nord, 1. 22 (832 śaka; IC III, p. 202) et K. 1198, face B, 1.50 ( $\mathrm{x}^{\mathrm{e}}$ śaka; NIC II-III, p. 245, Saveros Pou ne traduit pas ce passage). Dans tous ces cas, l'unité de mesure n'est pas précisée et devait être évidente pour les contemporains. La taille des rizières est parfois évaluée par des mesures telle que $v$ roh « une volée » (K. 89, 1. 5 ; 924 śaka ; IC III, p. 165 \& 167 n. 6), ou snāp, « un semis » (K. 760, 1. 22 ; IX śaka; IC V, p. 116, 117), qui semblent liées à la quantité de grain nécessaire pour ensemencer un champ. Dans d'autres cas, elle est également donnée par la quantité de riz récoltée (en je et lihh). Cependant, les mesures les plus fréquentes sont le pāda et le jen, qui sont vraisemblablement équivalentes. Saveros Pou définit le jen comme " une foulée ou une unité de labourage » (Pou 2004, s.v., p. 190) et pāda comme « une mesure de longueur (n. déterminée) », en supposant qu'elle était égale au jen (ibid., s.v., p. 310). Ce qui est certain, c'est que dans le cas du $p \bar{a} d a$, une seule mesure est nécessaire pour quantifier un terrain donné : sre pāda I dénote une rizière de 1 pāda $(\mathrm{K} .30,1.17$; $\mathrm{VI}^{\mathrm{e}}$ śaka; IC II, p. 27, 28), et le $p \bar{a} d a$ semble donc correspondre à une mesure de surface. L'inscription K. 790 confirme d'ailleurs que le pāda est directement lié au sanre (ou sare), classificateur le plus fréquent de rizières correspondant à des parcelles dont la surface n'est pas encore connue : sre 'āy 'āvāsa pāda kāc moy sanreyy, « rizière à 'Āvāsa, de chaque pāda est prélevé un sanrey» (1. 6-8; $\mathrm{vI}^{\mathrm{e}}$ śaka; IC V, p. 71-72).

Dans notre cas, ce sont au contraire deux mesures de longueur qui sont précisées. Il est peu vraisemblable qu'il s'agisse de brasses (vyāma), mesure qui est utilisée dans l'inscription K. 908 de Preah Khan pour évaluer la taille de l'enceinte et des douves ${ }^{124}$; la brasse est en effet évaluée généralement à environ 2 m (Cœdès 1941, p. 264), et il nous semble que cette terre atteindrait alors des proportions trop importantes $(31,2 \mathrm{ha})$. Il est donc possible de supposer que ces mesures étaient exprimées en coudées ( $h a t, h \bar{a} t$, sk. hasta). En se basant sur la stance XXVIII de l'inscription K. 675 et sur la hauteur du Prasat Thom de Koh Ker, Cœè̀s avait pu évaluer la coudée à $0,45 \mathrm{~m}$ (IXe śaka; IC I, p. 70) ; la parcelle couvrirait alors une superficie d'environ 1,58 ha.

Dans le cas de la deuxième rizière mesurée (face $\mathrm{A}, 1.37-39$ ), on notera que seule la longueur est précisée. À moins de supposer qu'une autre unité, de surface, est cette fois utilisée, on doit supposer que la deuxième dimension correspondait à une largeur « standard » de parcelle, que le lecteur contemporain était supposé connaître ou, plus simplement, que cette rizière mesurait $50[\times 50]$ coudées, soit une surface de $(50 \times 0,45)^{2}$ $\approx 506 \mathrm{~m}^{2}$. À terme, ces mesures devront être comparées à d'autres occurrences ainsi qu'à la distribution du parcellaire mis en évidence sur le terrain, afin de déterminer leur vraisemblance et leur constance éventuelle ; on notera que la contenance la plus fréquente des parcelles de petite taille mesurées par Pierre Bâty à Trapeang Thlok est d'environ $500 \mathrm{~m}^{2}$ (2005, p. 61-63).

\section{Face A, l. 17 : vamnola}

L'un des apports lexicographiques les plus importants de K. 1238 est sans doute la première occurrence du terme vamnola (pour vamnol), dérivé de vol « déclarer, se prononcer, déclamer » (Pou 2004, s.v., p. 457); les équivalents modernes de ces termes sont bol « to tell, say, speak ; to recite, relate... » et bamnol, /pumnoul/, « word, speech, saying, statement, dialogue; recitation; tale, story » (Headley et al. 1997, p. 844, 846). À propos de vol, Saveros Pou a noté que son usage en khmer angkorien en faisait « un

124. On notera que cette unité n'est jamais utilisée dans les parties khmères des inscriptions, mais que son usage est bien attesté en moderne (mod. bhyāma; Antelme 2004, p. 22). 
véritable homologue de kathă, sémantiquement et syntaxiquement », mais qu'il apparaît plus tardivement et « qu'il est plus limité dans l'usage et n'a pas subi de grammaticalisation » (Pou 1983, p. 350). En dehors de l'occurrence de la ligne A, 17, notre texte emploie systématiquement kathā. On pourra également faire le parallèle entre les expressions stap vamnola et stap vartamāna. La deuxième est généralement traduite par « écouter les nouvelles, les événements » (K. 165 N, 1. 17 ; 874 śaka; IC VI, p. 135). Cependant, si l'on considère l'autre traduction proposée par Saveros Pou pour vartamāna, « les faits » (Pou 2004, s.v., p. 433), il semble possible que ces deux expressions soient équivalentes. Enfin, on rappellera que, selon Saveros Pou, en moderne, le sens de vol est restreint à «"parler, dire" [...] et à "réciter les textes" dans la langue de théâtre » (Pou 1983, p. 354, 356, n. 40), ce qui « expliquerait le sens du dérivé baṃnol "récitatif, livret de théâtre" " (bātbamnol est d'ailleurs le nom du mètre khmer de la déclamation). Il est donc intéressant de noter que le dérivé nominal de vol est attesté au cours de la période angkorienne et apparaît dans un contexte administratif où son sens est plus près du témoignage officiel que de la déclamation littéraire.

\section{Face A, l. 23 : khloñ bhūtāśa vrah ratna}

À propos de khloñ bhūtāśa, cf. Sahai 1970, p. 116. La fonction que ce terme dénote reste malheureusement énigmatique. L'expression vrah ratna n'avait été relevée que dans la formule introductive du serment des fonctionnaires de Sūryavarman Ir ${ }^{\text {er }}$ qui devaient prêter serment vnek ni ta vrah vleñ vrah ratna nu vrāhmaṇācāryya, « en présence du Feu sacré, de/des vrah ratna et des brahmanes qui sont ācārya » (K. 292, 1. 3 ; 933 śaka; IC III, p. 208 - la traduction provisoire donnée est la nôtre). On ne sait pas encore avec certitude à quoi correspond vrah ratna d'autant que, dans une expression équivalente de la partie sanskrite inédite de l'inscription K. 1198, un fonctionnaire prête allégeance au même roi dvijavudhahutabhuksannidhau, «en présence de savants brahmanes et du feu », en omettant de mentionner un équivalent de vrah ratna (st. XXXIX; $\mathrm{X}^{\mathrm{e}}$ śaka). Dans son étude consacrée au serment des fonctionnaires de Sūryavarman Irer, Cœdès l'avait traduit par « saint Joyau », remarquant en note qu'il ignorait « ce qu'était ce joyau » et qu' « il est cité par ailleurs dans une inscription de Bantãy Čhmàr, [Aymonier, Le Cambodge], II, 344 » (1913, p. 15, n. 4). Il s'agit là de l'inscription K. 227, où l'on trouve plus précisément l'expression vrah grha ratna (1. 1 ; XII éaka; Cœdès 1929, p. 309). Or, Coedès lui-même avait expliqué grha ratna dans cette expression khmère comme équivalent du sanskrit ratnagrha qui « désigne le "saint des saints" d'un temple » (1928, p. 99). C'est dans ce vrah grha ratna que fut installée, selon l'inscription K. 227 et l'interprétation qu'en a donnée Cœedès, une image représentant un ministre (mantrī) défunt.

Quant au vrah ratna de notre inscription et du serment dans K. 292, nous proposons à titre d'hypothèse de traduire cette expression par « joyaux royaux » (au pluriel). Nous présupposons un lien avec les listes de sept, de neuf et même de quatorze ratna du cakravartin, l'idéal du roi universel, connues en littérature indienne (Norman 1983; Scharfe 1987). Un exemple typique d'une liste de sept ratna est celle que cite Rājaśekhara (vers 900 de n. è.) dans le $17^{\mathrm{e}}$ chapitre de sa Kāvyamìmāmssāa, sous la rubrique de cakravarticihnāni (éd. C. D. Dalal et R. A. Sastry, Baroda, 1934, p. 92) : 
cakraṃ ratho maṇir bhāryā nidhir aśvo gajas tathā |

proktāni sapta ratnāni sarveșạ̣̄ cakravartinām ||

« Le disque, le char, la pierre précieuse, l'épouse, le trésor, le cheval et l'éléphant,

voilà ce qu'on appelle les sept joyaux de tous les Cakravartin »

(trad. N. Stchoupak et L. Renou, La Kāvyamìmāmsā de Rājaśekhara, Paris,

1946, p. 241-242)

Dans d'autres listes figurent aussi des fonctionnaires tels le général (senāpatiratna) ou le chef des trésoriers (kośädhyakșa) - cf. Armelin 1975, p. 12 avec n. 40, p. 44. Si nous ne disposons pas de preuves positives textuelles assurant que de telles listes circulaient en Asie du Sud-Est à époque ancienne, il est tout de même sûr que les composants des listes ont joué des rôles importants dans la vie des cours royales (cf. par ex. Quaritch Wales 1931, index s.v. «Ratnas, royal »), et des représentations plastiques des saptaratna royaux ont également pu être identifiées dans la région (par ex. sur la base de la célèbre représentation d'Amoghapāśa de Rambahan, Sumatra, dans la collection du Musée national d'Indonésie : numéro d'inventaire D 198).

Il nous semble possible de distinguer le vrah grha ratna de K. 227 du vrah ratna qui nous concerne ici. Pourtant il faut noter l'association contextuelle de la première expression avec la fonction de mantrī, représentée - sinon littéralement, au moins par des exemples concrets tel le « trésorier »- dans certaines versions des listes classiques du monde indien parmi les « joyaux royaux ». Notre khloñ bhütāśa vrah ratna serait donc responsable, d'une façon indéterminable, de ces insignes et/ou fonctionnaires royaux, ou constituerait lui-même un de ces « joyaux ».

\section{Face A, l. 27 : daśagrāma}

Le composé daśagrāma, « dix villages », a été interprété à plusieurs reprises comme

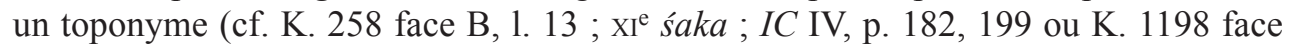
C, 1. 27 ; xe śaka; NIC II-III, p. 243, 249), mais le fait qu'il soit précisé ici que le Loñ 'Yak, daśagrāma, était du sruk de Vrah Kāṃ (face A, 1. 27-28), invite à mettre en doute cette conjecture. Saveros Pou a proposé deux autres hypothèses. Elle interprète d'abord daśagrāma (K. 258, face B, 1. 13) par « fait de dix villages » et il faudrait donc traduire l'expression khloñ sruk daśagrāma par « chef d'une commune composée de dix villages » (Pou 2004, s.v., p. 248). D'autre part, elle comprend daśagrāma comme un anthroponyme dans l'inscription K. 598 : Vāp Daśagrāma (face B, 1. 25), Vāp Su-Daśagrāma (face $\mathrm{B}, 1.26$ ) ; elle ne prend pas en compte le vāp pa daśagrāma (face $\mathrm{B}, 1.28$ ) dans sa traduction (NIC II-III, p. $232 \& 235$ ). Nous avons privilégié ici l'interprétation proposée par Louis Finot pour cette même inscription : «Le Vāp chef de dix villages »; «Les Vāp Sur et Vāp Pa, chefs de dix villages » (1928, p. 68, 77). Cette traduction a été reprise par Sachchidanand Sahai (1970, p. 83), qui a proposé de voir dans les khloñ sruk daśagrāma ou daśagrāma, par abréviation, des chefs d'unités administratives de dix villages, interprétation qui correspondrait assez bien avec la première hypothèse de Pou. Il semble d'ailleurs que ce type de regroupement de villages soit également attesté en Inde (Sircar 1966, s.v. dāśagrāmika, p. 84 : « the headman of a group of ten villages or the chairman of the council of a group of ten villages »; voir aussi Kautilya, Arthaśāstra 2.1.4 et 2.35.2, éd. R. P. Kangle, Bombay 1969).

Par ailleurs, on notera que le composé śatagrāma, « cent villages », apparaît également à plusieurs reprises dans les inscriptions. L'hypothèse d'un toponyme a souvent été privilégiée (par ex. sruk śatagrāma, « la commune de Śatagrāma », K. 235 face C, 
1. 59 ; 974 śaka; Sak-Humphry 2005, p. 95). Dans l'inscription K. 989, śatagrāma a même été considéré comme le nom d'une unité administrative de type pramān (face B, 1. 8 ; 930 śaka ; IC VII, p. 175). La mention d'un śatagrāmāaddhyakșa, « chef de cent villages » ou « chef de [la commune de] Śatagrāma », dans l'inscription K. 1215 (1. 1 ; VI-VII ${ }^{\mathrm{e}}$ saka) ${ }^{125}$ laisse également place aux deux interprétations. Selon Sahai, il s'agirait pourtant plus vraisemblablement d'une autre unité administrative, composée cette fois de cent villages (1970, p. 83).

\section{Face A, l. 29 : pādamūla vrah hemaśrñn][ga]/giri}

Le temple Hemaśrngagiri, « Mont de la corne d'or » ou « Mont à la cîme d'or », est également nommé hemagiri, « Mont d'or », et correspond vraisemblablement au Prasat Ta Keo (Cœdès 1934). Saveros Pou note à propos de hemaśrngagiri : « Site du Baphuon, d'après GC », tout en indiquant que hemaśrniga est le nom « du Prasat Ta Kèv, appelé aussi hemagiri» (Pou 2004, s.v., p. 550). La première hypothèse est plutôt attribuable à Étienne Aymonier (1904, p. 495), et avait été contredite par George Cœè̀s qui identifiait le Baphuon au svarṇādri de l'inscription de Lovek (K. 136; x śaka; Cœdès 1931). En effet, quelle que soit la complexité des différentes phases de construction du Baphuon, il semble que l'essentiel de la construction de ce temple soit attribuable au règne d'Udayādityavarman II et qu'on ne puisse attribuer, au mieux, que la paternité du projet à son prédécesseur, Sūryavarman $I^{\mathrm{er}}$. De toutes façons, plusieurs inscriptions attestent le fait que le hemaśrringagiri était au moins en cours de construction sous le règne de Jayavarman V, et ne saurait donc correspondre au Baphuon (Cœdès 1931, p. 18-20).

Littéralement « la plante des pieds », le terme pādamūla est également une expression polie, en sanskrit, pour désigner des personnes (cf. Monier-Williams, s.v., p. 617). Les dictionnaires de référence ne signalent pas l'usage de ce terme, pourtant assez fréquent, dans l'épigraphie sanskrite indienne - par exemple dans le corpus des Maitraka, à partir $\mathrm{du} \mathrm{VII}^{\mathrm{e}}$ siècle de notre ère -, où il désigne spécifiquement un personnage important dans la gestion de temples ou de monastères (cf. Schmiedchen 1993a, p. 92-93 ; 1993b, p. 590591). Il apparaît au Cambodge dans ce sens essentiellement dans les parties khmères des inscriptions ; George Cœdès traduit ainsi régulièrement ce terme par « honorable », « respectable » ou « vénérable ». Cette interprétation semble en effet correcte dans l'inscription préangkorienne K. 127, 1. 9 : pādamūla ta 'anau varī panlas I viśeșa ${ }^{126}$ gup I « personnes respectables demeurant (ici) : 1 varī suppléant, 1 gardien spécial » (604 śaka ; IC II, p. 89, 90) ; c’est probablement également le cas dans les autres inscriptions préangkoriennes dans lesquelles ce terme a été relevé (K. 154, face A 1.16 ; 656 śaka; IC II, p. 124 et K. 726, 1. 12, 13, 18 ; vII śaka; IC V, p. 76). Pourtant, Codès remarque par ailleurs que « ce mot semble désigner généralement le chef, le supérieur ou le gardien d'un āçrama » (IC IV, p. 196, n. 4). En effet, pādamūla correspond apparemment à une position hiérarchique élevée dans plusieurs occurrences, généralement dans des inscriptions explicitement liées à des āśrama, toutes de la période angkorienne, et il est possible que son sens ait alors évolué (pādamūla vrah 'áśrama ; K. 153, 1. 7-8 ; 923 śaka ? IC V, p. 195). Il semble que cette position n'était pas occupée par un unique

125. Notre lecture est fondée sur l'examen d'un cliché communiqué au « Corpus des inscriptions khmères » par Michel Tranet. Cette inscription a été publiée sous le numéro Ka 24 par Saveros Pou et Vong Sotheara, qui proposent les lectures śatrkramādtyakșa (NIC II-III, p. 184) et śatakramādtyakșa (Vong Sotheara 2003, p. 45-46).

126. La leçon viśesa proposée par Cœdès est erronée. 
dignitaire dans un sanctuaire ou un āśrama donné. Dans l'inscription K. 684, on relève en effet la séquence suivante : loñ rau nu loñ prāṇa pādamūla kamratè jagat vnam kantāl «Loñ Rau et Loñ Prāṇa, vénérables du Kamrateñ Jagat du Phnom Bakheng » (1. 7-9 ; IX-Xe śaka; IC IV, p. 106); si, comme le pense Cœedès, pādamūla qualifie bien les deux Loñ, alors il est possible que, dans notre cas, le Loñ 'Yak du sruk de Vāruni n'était pas le vénérable proprement dit du Prasat Ta Keo, mais seulement l'une des personnes qui $\mathrm{y}$ portait ce titre, et dont la fonction ou le statut restent à préciser.

\section{Face A, l. 42-44 : kphvar et spek}

Ce passage permet deux avancées en lexicographie du vieux khmer.

Dans son introduction à l'édition de K. 542 ( $\left.\mathrm{x}^{\mathrm{e}} s a k a\right)$, inscrite sur les piédroits de la porte sud du Prasat Khleang Nord, Cœedès a noté que « au-dessous de la partie inscrite, deux plans orientés comme nos cartes, nord en haut et est à droite, répètent d'une manière graphique les indications du texte relatives à la limite des deux terrains et à leur division en plusieurs parcelles. Le plan du haut est celui de la terre de Cvar Saṃñā, celui du bas très abîmé n'a pas mieux conservé que le texte le nom du domaine qu'il représente. » (IC III, p. 222). Le mot kphvar s'y trouve inscrit dans la légende neh gi khpvar bhümi cvar samiña a « Ceci est le khpvar de la terre de Cvar Samiñā ». Il semble que le mot khpvar était la désignation en vieux khmer de tels plans. Le dictionnaire de Saveros Pou (2004, s.v., p. 128) ignore l'occurrence de K. 542. Sa glose « Dessin, motif » se base sur le sens de $g \bar{u} r,{ }^{\circ} k p \bar{u} r$ dans la langue moderne (Pou 1992, p. 3-14. et 2004, s.v., p. 128) ainsi que sur deux occurrences épigraphiques peu éclaircissantes. Le contexte de celle de K. 549 (1. 25 ; XII-XIII śaka ? ;C II, p. 156) est trop lacunaire pour soutenir une quelconque glose ; l'occurrence dans K. 470, 1.22 (1249 śaka; IC II, p. 188 et 189) est également problématique : san thma goll racanā khpvar vin. Cœedès a traduit cette séquence par « plantant à nouveau les bornes ornées de motif décoratifs ", mais des traductions alternatives telles que « érigeant les pierres en tant que bornes, dressant à nouveau le plan » ou «érigeant à nouveau les pierres en tant que bornes, ornées de plans » paraissent aussi convaincantes. Dans ce dernier passage, il semble que racanā khpvar, avec racanā (emprunt au sanskrit) en fonction probablement verbale, équivaut à l'expression thve khpvar trouvée à trois reprises dans le présent passage de K. 1238. Le cas de K. 542 montre que des kphvar pouvaient être dressés sur pierre, mais l'absence d'autres plans de l'époque angkorienne suggère qu'ils l'étaient normalement sur des matériaux périssables.

Comme l'a noté Saveros Pou (1992, p. 14), la pierre ne constituait effectivement « pas le seul matériau connu des Khmers » comme support d'écriture ; « les voyageurs chinois anciens mentionnaient l'usage de la peau également, mais nous n'en possédons pas de témoignage lexical dans les inscriptions ». Notre passage fournit maintenant ce témoignage, en donnant la première attestation du mot spek, «cuir» (cf. khm. mod. /sbaek/, Headley et al. 1997, p. 1384, « skin, leather, hide »), jusqu'ici inconnu en vieux khmer. Les détails des rapports chinois sont cités par George Groslier (1921, p. 3, et 381382 pour les notes), qui renvoie également à l'importante st. LXXXIV de l'inscription K. 290, qui énumère les fournitures nécessaires aux étudiants pour l'écriture.

Enfin, Hubert de Mestier du Bourg avait déjà souligné que certaines inscriptions témoignent de l'usage de preuves écrites au cours de procès datant de la période angkorienne (1968, p. 39). Ce plan sur cuir en constitue un nouvel et original exemple. 

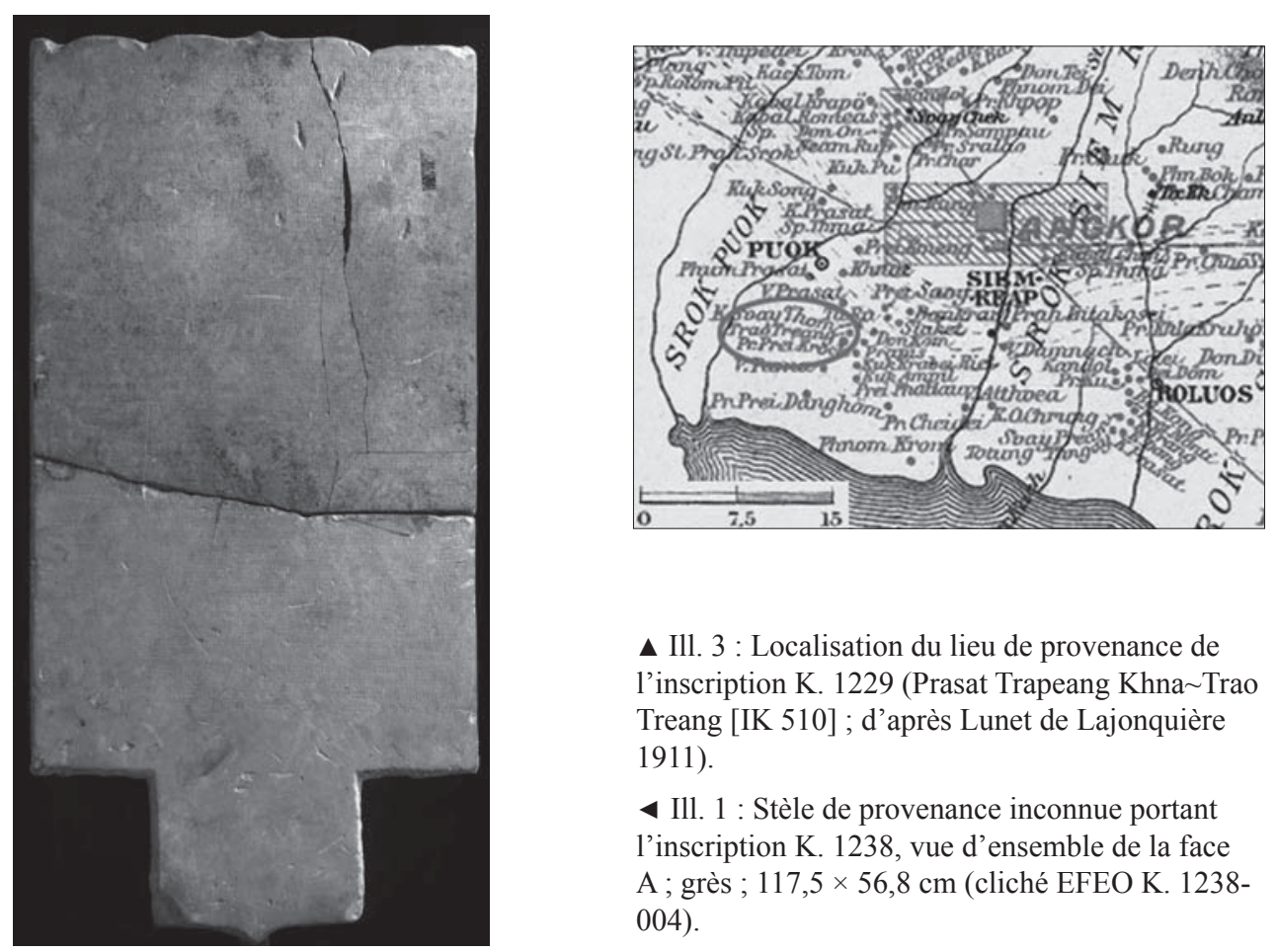

A Ill. 3 : Localisation du lieu de provenance de l'inscription K. 1229 (Prasat Trapeang Khna Trao Treang [IK 510] ; d'après Lunet de Lajonquière 1911).

4 Ill. 1 : Stèle de provenance inconnue portant l'inscription K. 1238, vue d'ensemble de la face $\mathrm{A}$; grès ; 117,5 × 56,8 cm (cliché EFEO K. 1238004).

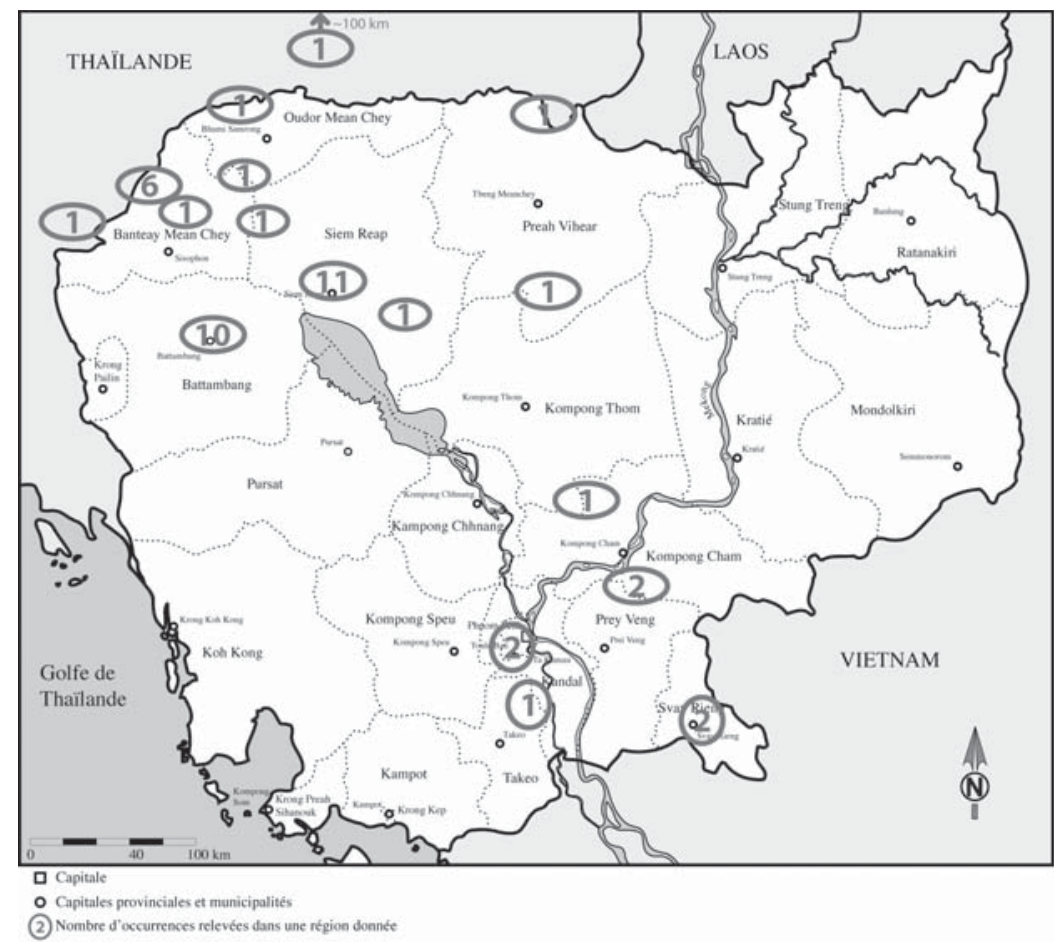

\ Ill. 2 : Répartition géographique des inscriptions khmères mentionnant des toponymes relevés dans l'inscription K. 1238. 


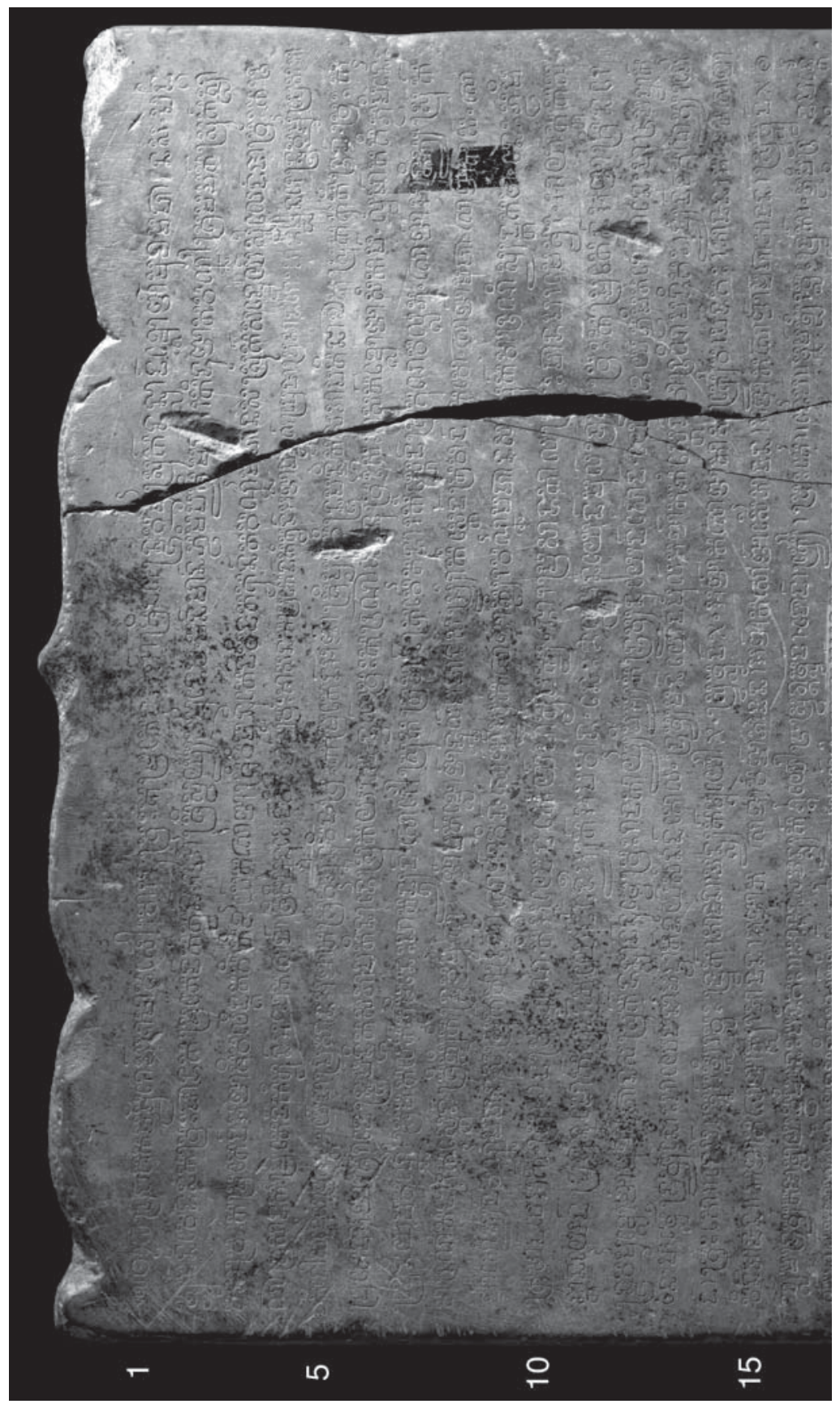

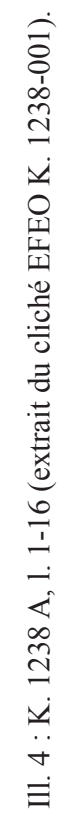




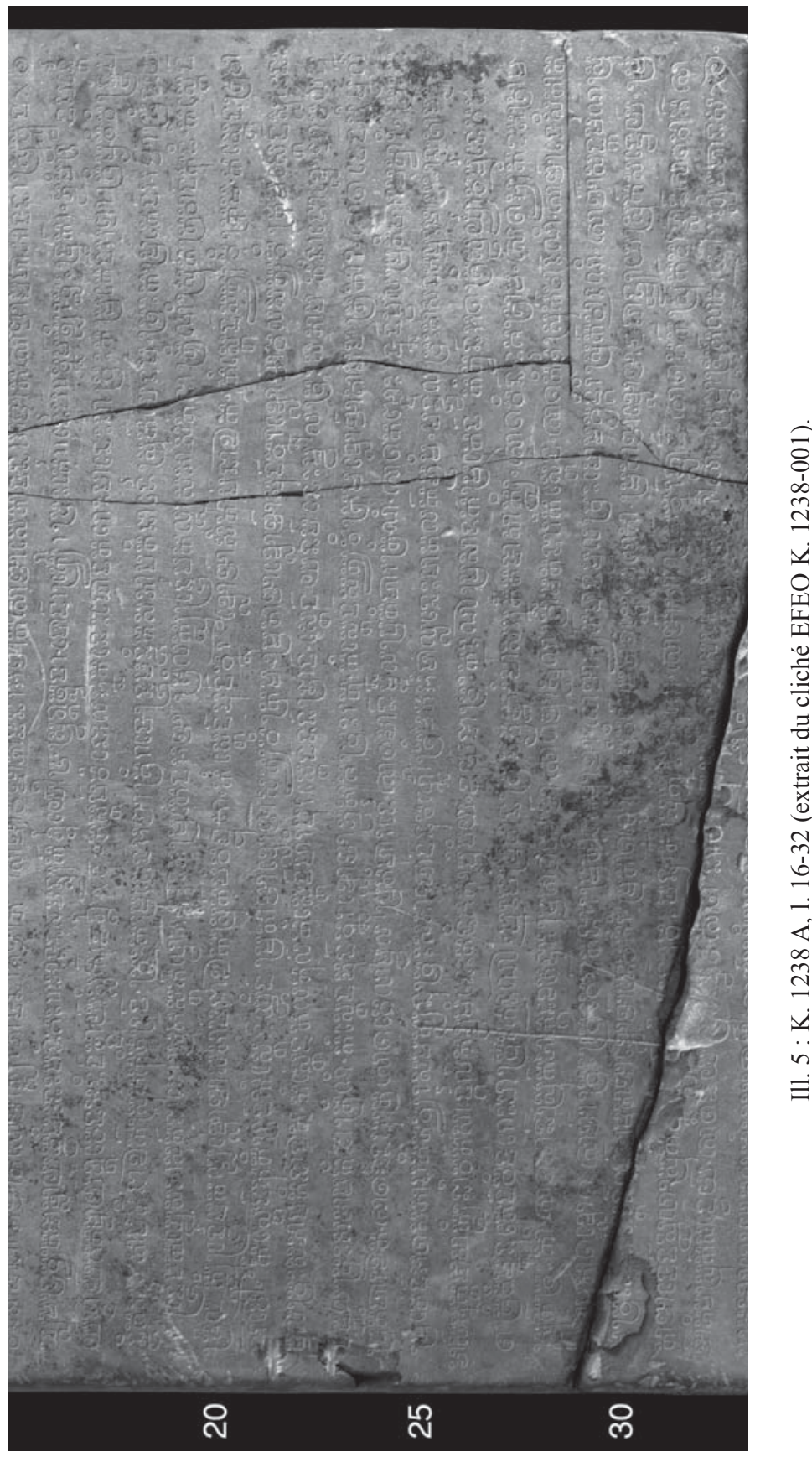




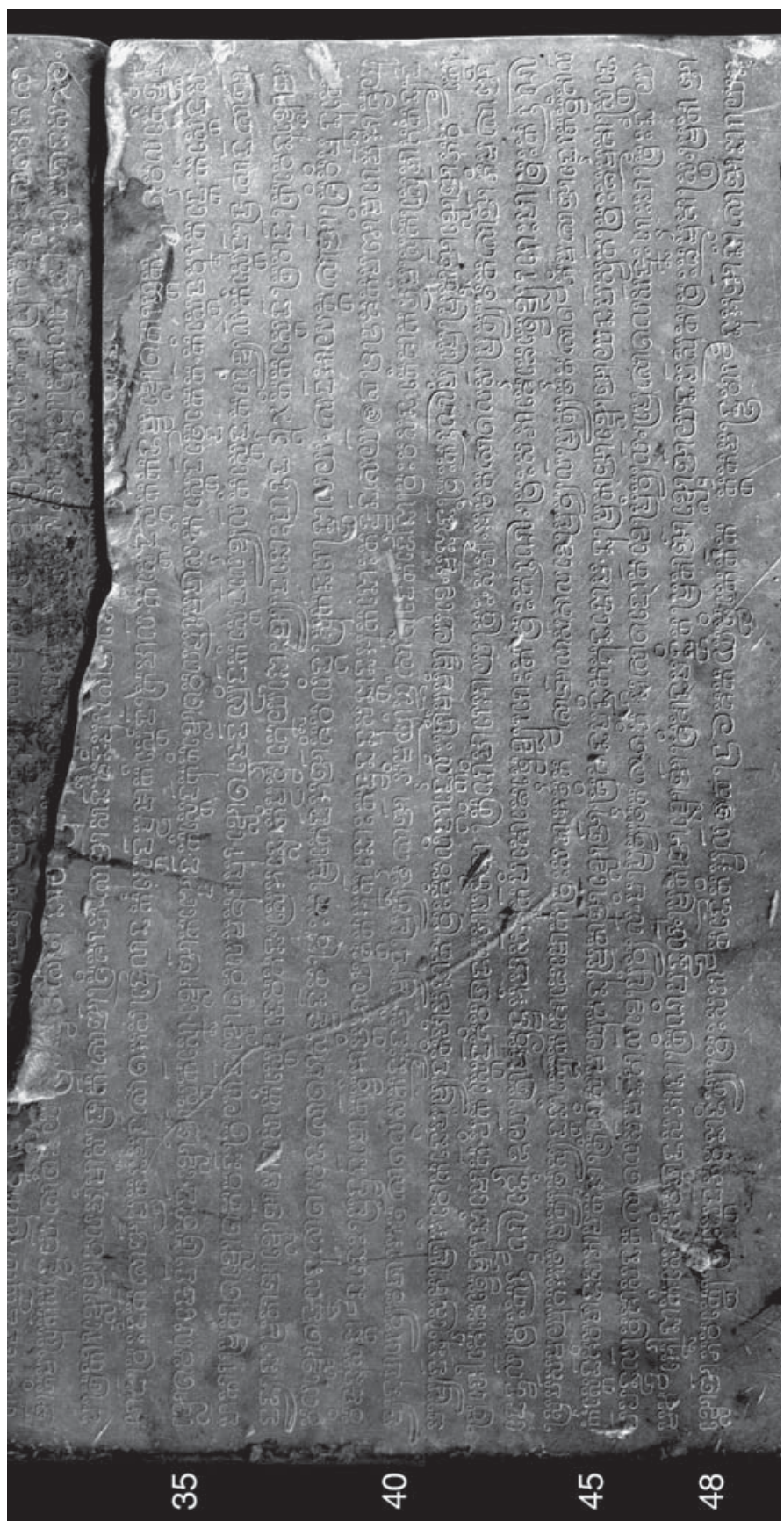

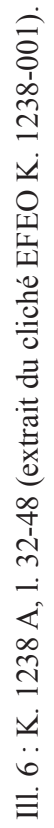




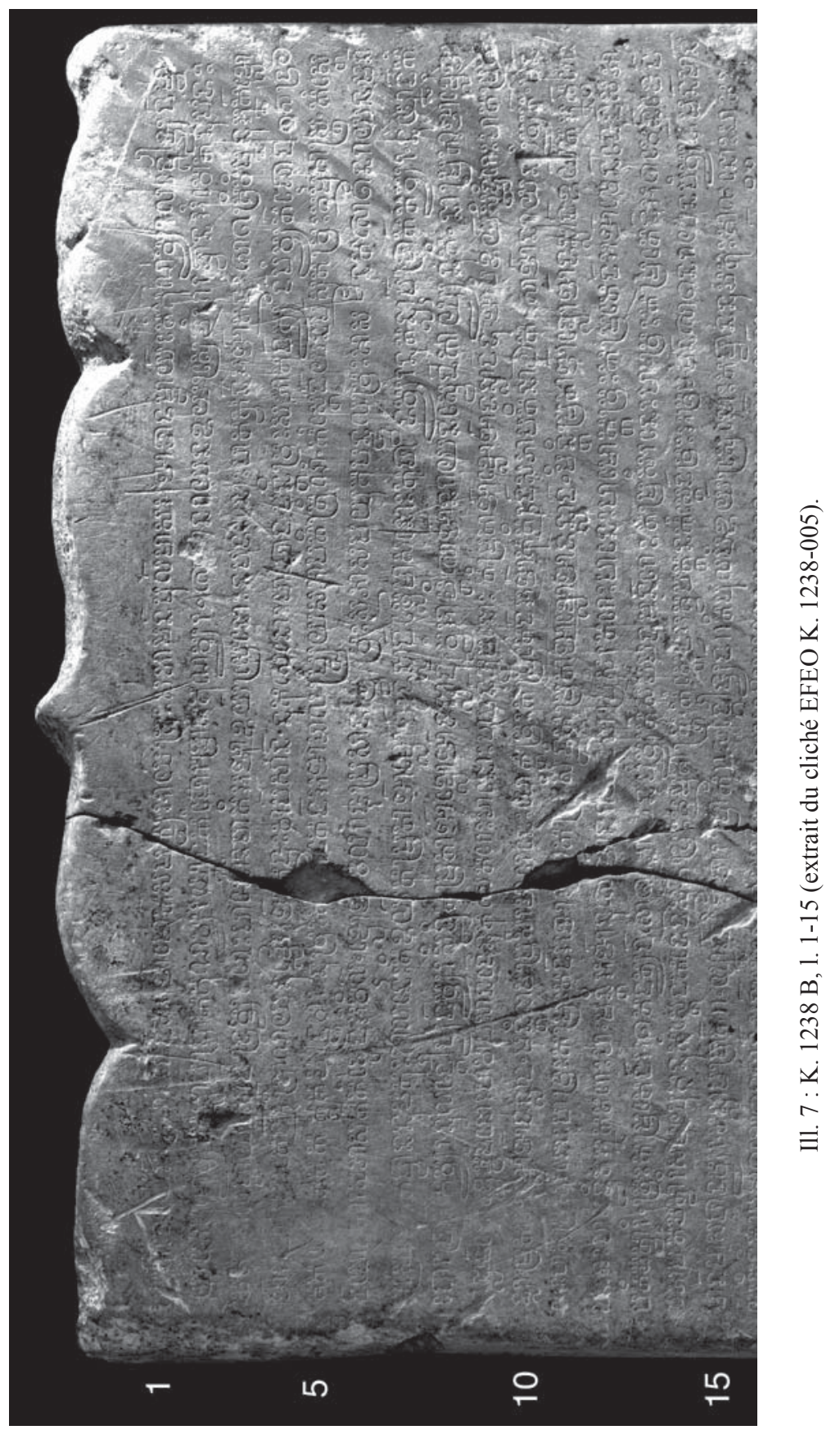




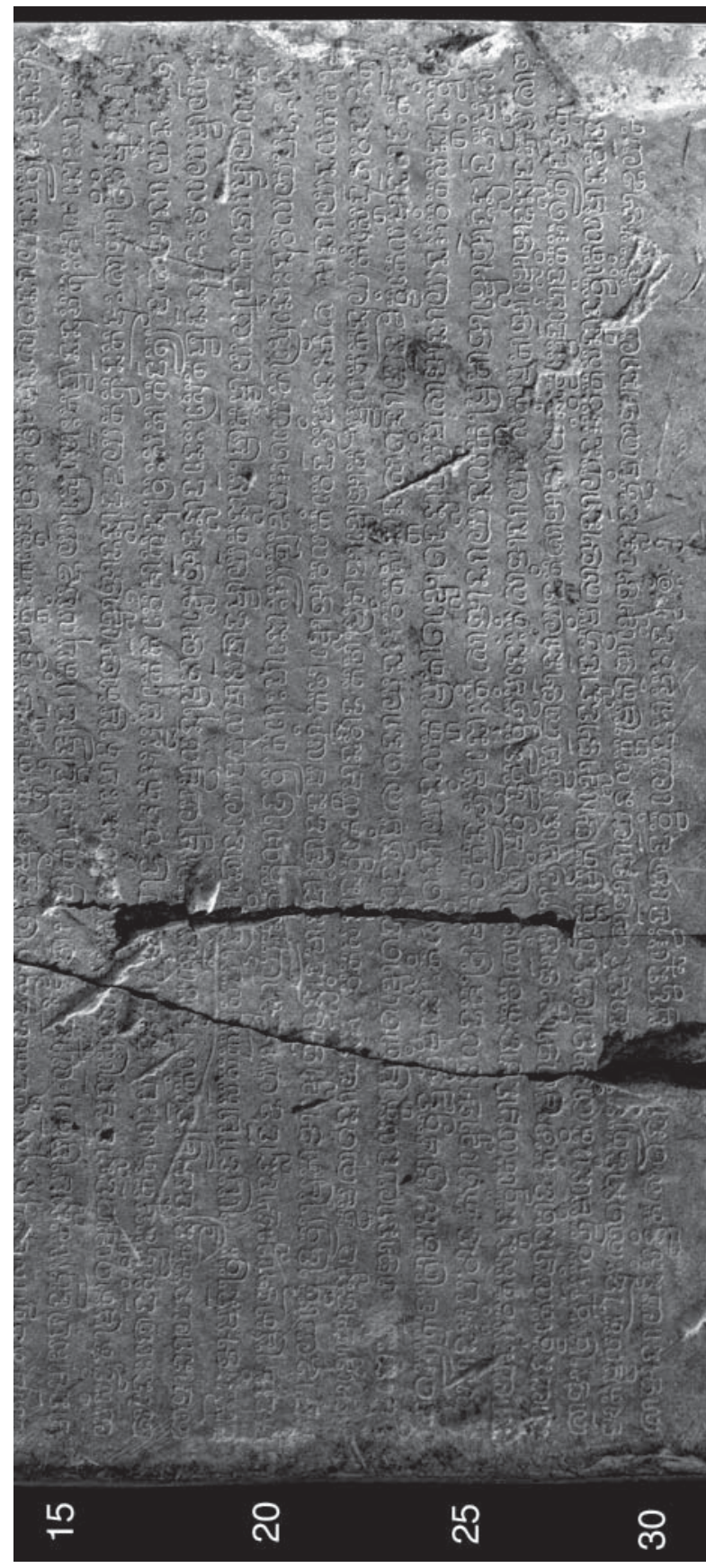

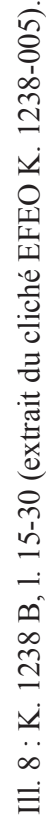




\title{
Bibliographie
}

\author{
APK Articles sur le pays khmer; cf. CEDÈs 1989/1992. \\ IC Inscriptions du Cambodge; cf. CEDÈs 1937-1966. \\ ISC Inscriptions sanscrites du Cambodge : cf. BARTH 1885. \\ ISCC Inscriptions sanscrites de Campā et du Cambodge : cf. BergaIGNE 1893. \\ NIC II-III Nouvelles inscriptions du Cambodge II-III ; cf. Pou 2001.
}

Antelme, Michel

2004 «À propos d'un texte sur les nombres, les mesures traditionnelles, etc., rédigé par le Hluon Bibhăkti Dhānī, Yokpătr de Chrui Changva, pour Adhémard Leclère », Siksācakr 6, p. 20-32.

2007 «Inventaire provisoire des caractères et divers signes des écritures khmères pré-modernes et modernes employés pour la notation du khmer, du siamois, des dialectes thaïs méridionaux, du sanskrit et du pāli », Bulletin en ligne de l'AEFEK 12, juin 2007 [+ « Avant-propos » de l'auteur ; les deux documents sont au format pdf; publication électronique consultée en juin 2008].

Armelin, Indumati

1975 Le Roi détenteur de la roue solaire en révolution (cakravartin) selon le brahmanisme et selon le bouddhisme, Paris, Geuthner.

AyMONIER, Étienne

1904 Le Cambodge, tome III, Le groupe d'Angkor et l'histoire, Paris, Ernest Leroux.

BARTH, Auguste

1885 Inscriptions sanscrites du Cambodge, Paris, Imprimerie nationale (notices et extraits des manuscrits de la Bibliothèque nationale et autres bibliothèques, tome XXVII, $1^{\text {re }}$ partie, $1^{\text {er }}$ fasc.).

BÂTY, Pierre

2005 Extension de l'aéroport de Siem Reap, " Trapeang Thlok-Prasat Trapeang Ropou », rapport de diagnostic archéologique, "Trapeang Thlok-sanctuaire et habitat " rapport de fouille, document final de synthèse de sauvetage urgent, base INRAP de Poitiers [avec la collaboration de Annie Bolle, JeanBaptiste Chevance, Armand Desbat, Leang Hong, Noun Narak, Sandrine Marquie, Phoeung Dara, Christelle Seng, Tan Boun Suy, Jean-Hervé Yvinec].

Bergaigne, Abel

1893 Inscriptions sanscrites de Campā et du Cambodge, Paris, Imprimerie nationale (notices et extraits des manuscrits de la Bibliothèque nationale et autres bibliothèques, tome XXVII, $1^{\text {re }}$ partie, $2^{\mathrm{e}}$ fasc.).

BhATTACHARYa, Gouriswar (éd.)

1986 Deyadharma: Studies in memory of Dr. D. C. Sircar, Delhi, Sri Satguru Publications.

BHATTACHARYA, Kamaleswar

1991 Recherches sur le vocabulaire des inscriptions sanskrites du Cambodge, Paris, EFEO (PEFEO 167). 
BILlARD, Roger \& J. C. EADE

2006 « Dates des inscriptions du pays khmer », BEFEO 93, p. 395-428 [paru en 2008].

Chaem Kaewrlai

1999 «Inscription on Ancie[n]t Stone Temple of Tameunthom », The Silpakorn Journal 42/2, March-April 1999, p. 70-92.

Chakravarti, Adhir

1982 Royal Succession in Ancient Cambodia, Calcutta, The Asiatic Society.

Chirapat Prapandvidya

1990 «The Sab Bāk Inscription: Evidence of an Early Vajrayana Buddhist Presence in Thailand », The Journal of the Siam Society 78/2, p. 11-14.

CEDÈs, George

1911 "Les deux inscriptions de Vat Thĭpděi, Province de Siem Rãp », dans Mélanges d'indianisme offerts par ses élèves à M. Sylvain Lévi, Paris, p. 213-229.

1913 «Études cambodgiennes IX. Le serment des fonctionnaires de Sūryavarman I », BEFEO 13/6, p. 11-17 [Réimpr. APK I, p. 27-33, manque les pages 15-16].

1928 "Études cambodgiennes XIX. La date du Bàyon », BEFEO 28, p. 81-112 [Réimpr. $A P K \mathrm{I}$, p. 95-126].

1929 « Études cambodgiennes XXIV. Nouvelles données chronologiques et généalogiques sur la dynastie de Mahīdharapura », BEFEO 29, p. 297-330 [Réimpr. $A P K \mathrm{I}$, p. 169-202].

1931 «Études cambodgiennes XXVII. La date du Bàphûon », BEFEO 31/1-2, p. 18-23 [Réimpr. $A P K$ I, p. 220-225].

1934 « La date du Tà Kèv. III. épigraphie », BEFEO 34/2, p. 417-427 [Réimpr. $A P K$ II, p. 69-79].

1936 «Études cambodgiennes XXXII. La plus ancienne inscription en pāli du Cambodge ", BEFEO 36/1, p. 14-21 [Réimpr. APK 1, p. 282-289].

1937-66 Inscriptions du Cambodge (8 vol.), Hanoi/Paris, Imprimerie d'ExtrêmeOrient/EFEO.

1941 «La stèle du Práh Khằn d'An̉kor », BEFEO 41/2, p. 255-302 [Réimpr. APK II, p. 119-166].

1989/92 Articles sur le pays khmer (2 vol.) [Réimpr. des articles sur le Cambodge parus dans le $B E F E O$ et dans les $C E F E O]$, Paris, EFEO (Réimpressions).

CEEDÈs, George \& Pierre DuPONT

1937 « Les inscriptions du Pràsàt Kôk Pô », BEFEO 37, p. 379-413 [Réimpr. $A P K$ II, p. 81-115].

1943-46 « Les stèles de Sdŏk Kăk Thoṃ, Phnoṃ Sandak et Práh Vihār », BEFEO 43, p. 56-154 [Réimpr. APK II, p. 167-265].

EADE, J.C.

2008 «Computers vs Tables, Billard vs Golzio: Two New Date-Lists of the Inscriptions of Kamboja », Zeitschrift der Deutschen Morgenländischen Gesellschaft 158/1, p. 73-104.

FinOT, Louis

1928 « Nouvelles inscriptions du Cambodge », BEFEO 28, p. 43-80. 
GREEN, Gillian

2000 "Indic Impetus? Innovations in Textile Usage in Angkorian Period Cambodia », Journal of the Economic and Social History of the Orient 43/3, p. 277-313.

Griffiths, Arlo (en coll. avec J. C. EAdE et Gerdi GersChHEIMER)

2005 « La stèle d'installation de Śrī Tribhuvaneśvara : une nouvelle inscription préangkorienne du musée national de Phnom Penh (K. 1214) », Journal asiatique 293/1, p. 11-43.

Griffiths, Arlo \& William A. SOUthworth

2007 « La stèle d'installation de Śrī Satyadeveśvara : une nouvelle inscription sanskrite du Campā trouvée à Phước Thiện ", Journal asiatique 295/2, p. 349-381.

GrosLIER, George

1921 Recherches sur les Cambodgiens, Paris, Augustin Challamel.

Headley, Robert K. Jr., Chin Rath \& Soeum OK

1997 Modern Cambodian English Dictionary, Kensington, Dunwoody press.

JACOB, Judith M.

1991 «A diachronic survey of some Khmer particles (7th to 17th centuries) », dans J. H. C. S. DAvidson (éd.), Austroasiatic Languages. Essays in honour of H. L. Shorto (London, School of Oriental and African studies), p. 193-225.

1993 Cambodian Linguistics, Literature and History. Collected Articles, édité par David A. Sмүтн, London, School of Oriental and African studies.

JENNER, Philip N.

1981 A Chrestomathy of Pre-Angkorian Khmer. II: Lexicon of the dated Inscription, Hawai' $i$, University of Hawai' $i$ at Manoa, Center for southeast Asian studies. School of Hawaiian, Asian, and Pacific Studies (Southeast Asia Paper n ${ }^{\circ} 2$, part 4).

Kalista, Kathleen \& Carlton C. Jr. RochelL

2007 Pantheon of the gods. Art from India and Southeast Asia, New York, Carlton Rochell Asian Art.

KOURILSKY, Grégory

2008 " Note sur la piété filiale en Asie du Sud-Est theravādin : la notion de "gụ̣" ", Aséanie 20, p. 27-54.

Lewitz, Saveros

1970 «Recherches sur le vocabulaire cambodgien (VI). Les noms des points cardinaux en khmer », Journal asiatique 258, p. 131-141.

LONG SEAM

1993 « Les noms géographiques khmers d'après les inscriptions du Cambodge », Mon-Khmer Studies 22, p. 127-147.

s. d. Dictionnaire du khmer ancien (d'après les inscriptions du Cambodge du vleVIII ${ }^{e}$ siècles), Phnom Penh Printing House.

LuNET DE LAJONQUière, É[tienne]

1911 Inventaire descriptif des monuments du Cambodge, t. III, Paris, Ernest Leroux. 
MabBetT, I[an] W.

1977 « Varnas in Angkor and the Indian Caste System », Journal of Asian Studies 36/3, p. 429-442.

Mestier Du Bourg, Hubert de

1968 " Le procès dans l'ancien droit khmer, d'après l'épigraphie », Journal asiatique 256, p. 37-53.

Monier-WiLliams, Monier

1899 A Sanskrit-English dictionary, Oxford, Clarendon press [rééd. 1990, Delhi].

NORMAN, K. R.

1983 « The Nine Treasures of a Cakravartin », Indologica Taurinensia 11, p. 183-193.

Pou, Saveros

1983 "Recherches sur le vocabulaire cambodgien (XI). Des verbes "parler" en khmer », Journal asiatique 271/4, p. 345-362.

1989 " Sanskrit Loanwords in Old Khmer: Some morphological Observations », dans Colette Caillat (éd.), Dialectes dans les littératures indo-aryennes (Paris, Collège de France [Publications de l'Institut de civilisation indienne 55]), p. 569-578 [Réimpr. Pou 2003, p. 271-280].

1992 « Des mots khmers désignant les "documents écrits" », Mon-Khmer Studies 20, p. 11-17.

2001 Nouvelles inscriptions du Cambodge II \& III, Paris, EFEO (Collection de textes et documents sur l'Indochine 22-23).

2002 «Áśrama dans l'ancien Cambodge », Journal asiatique 290/1, p. 315-339.

2003 Choix d'articles de khmérologie / Selected papers on khmerology, Phnom Penh, Reyum.

2004 Dictionnaire vieux khmer-français-anglais / An Old Khmer-French-English dictionary / Vacanānukram khmaer cās'-pārāmin-añles, Paris / Budapest / Torino, L'Harmattan [ [2 édition $=1^{\text {re éd. }}$ (1992) + supplément].

Quaritch Wales, H. G.

1931 Siamese State Ceremonies. Their history and function, London, Bernard Quaritch Limited.

RICKLEFS, M. C.

1967 "Land and the Law in the Epigraphy of Tenth-Century Cambodia », Journal of Asian Studies 26/3, p. 411-420.

Roth, Gustav

1986 " Mangala-Symbols in Buddhist Sanskrit Manuscripts and Inscriptions ", dans G. Bhattacharya (éd.) 1986, p. 239-249.

SAHAI, Sachchidanand

1970 Les institutions politiques et l'organisation administrative du Cambodge ancien (VI ${ }^{e}$-XIII siècles), Paris, EFEO (PEFEO 75).

SAK-Humphry, Chhany (with the assistance of Philip N. JenNer)

2005 The Sdok Kak Thom Inscription (K. 235). With a Grammatical Analysis of the Old Khmer Text, [Phnom Penh], Buddhist Institute.

SANDER, Lore

1986 « Om or Siddham - Remarks on Openings of Buddhist Manuscripts and Inscriptions from Gilgit and Central Asia », dans G. BhatTacharya (éd.) 1986, p. 251-261. 
SCHARFE, Hartmut

1987 «Zur Einsetzung des Königs im vedischen Indien », Studien zur Indologie und Iranistik 13/14, p. 185-193.

SCHMiEDCHEN, Annette

1993a «Einige Besonderheiten der buddhistischen Schenkungsinschriften unter den Maitrakas », Beiträge des Südasien-Instituts 1. Sonderheft, p. 83-108.

1993b « Formulas determining the purposes of donations to Buddhist monasteries in West and East India from the 5th to the 9th century A.D. », dans Adalbert Gail \& Gerd J. R. Mevissen (éd.), South Asian Archaeology 1991, Stuttgart, Franz Steiner Verlag, p. 585-593.

SIRCAR, D. C.

1966 Indian Epigraphical Glossary, Delhi, Motilal Banarsidass.

SoutiF, Dominique

2009 « Organisation religieuse et profane du temple khmer du VII au XIII siècle », thèse de doctorat sous la direction de Michel Jacq-Hergoualc'h, Université Paris III Sorbonne nouvelle, 3 vol.

VICKERY, Michael

1985 « The Reign of Sūryavarman I and Royal Factionalism at Angkor », Journal of Southeast Asian Studies 16/2, p. 226-244.

1992 «Evidence for Prehistoric Austronesian-Khmer Contact and Linguistic Borrowing », Mon-Khmer Studies 21, p. 185-189.

1998 Society, Economics, and Politics in Pre-Angkor Cambodia. The 7th-8th Centuries, Tokyo, The Centre for East Asian Cultural Studies for Unesco, The Toyo Bunko.

VONG SOTHEARA

2003 Silācārịk nai prades Kambujā samăy mun Aingar, 1, Atthapad pak prae, rīep rìen nin atthādhippāy [Inscriptions préangkoriennes du Cambodge, 1, textes traduits, compilés et commentés], Phnom Penh, Université royale de Phnom Penh, Faculté de sociologie et de sciences humaines, département d'histoire.

2005 «Anew Angkorian inscription found at Banteay Chmar Ka $442 »$, Dassanāvatțī Sañgamasāstr-Manussasāstr 50, p. 11-15. 